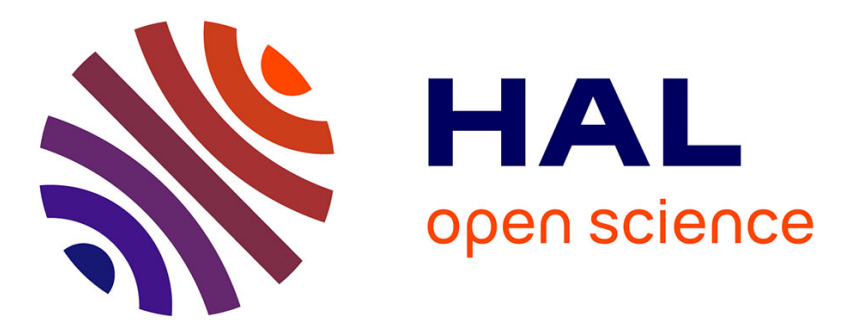

\title{
Interannual relationships between Indian Summer Monsoon and Indo-Pacific coupled modes of variability during recent decades
}

Ghyslaine Boschat, Pascal Terray, Sébastien Masson

\section{- To cite this version:}

Ghyslaine Boschat, Pascal Terray, Sébastien Masson. Interannual relationships between Indian Summer Monsoon and Indo-Pacific coupled modes of variability during recent decades. Climate Dynamics, 2011, 37, pp.1019-1043. 10.1007/S00382-010-0887-Y . hal-00758316

\section{HAL Id: hal-00758316 https://hal.science/hal-00758316}

Submitted on 29 May 2016

HAL is a multi-disciplinary open access archive for the deposit and dissemination of scientific research documents, whether they are published or not. The documents may come from teaching and research institutions in France or abroad, or from public or private research centers.
L'archive ouverte pluridisciplinaire $\mathbf{H A L}$, est destinée au dépôt et à la diffusion de documents scientifiques de niveau recherche, publiés ou non, émanant des établissements d'enseignement et de recherche français ou étrangers, des laboratoires publics ou privés. 


\author{
Interannual relationships between Indian Summer Monsoon \\ and Indo-Pacific coupled modes of variability \\ during recent decades
}

Ghyslaine Boschat ${ }^{1}$, Pascal Terray, Sébastien Masson

\title{
LOCEAN/IPSL, CNRS/IRD/UPMC/MNHN, Paris, France
}

Submitted to Climate Dynamics

Revised June 2010

\footnotetext{
${ }^{1}$ Corresponding author address : Ghyslaine Boschat, LOCEAN-IPSL, Université Pierre et Marie Curie, BP100 - 4 place Jussieu, 75252 Paris cedex 05, France.

Tel : +3314427 7078

E-mail : gbolod@locean-ipsl.upmc.fr
} 


\begin{abstract}
Various SST indices in the Indo-Pacific region have been proposed in the literature in light of a long-range seasonal forecasting of the Indian Summer Monsoon (ISM). However, the dynamics associated with these different indices have never been compared in detail.
\end{abstract}

To this end, the present work re-examines the variabilities of ISM rainfall, onset and withdrawal dates at interannual timescales and explores their relationships with El NiñoSouthern Oscillation (ENSO) and various modes of coupled variability in the Indian Ocean. Based on recent findings in the literature, five SST indices are considered here: Niño3.4 SST index in December-January both preceding (Nino(-1)) and following the ISM (Nino(0)), South East Indian Ocean (SEIO) SST in February-March, the Indian Ocean Basin (IOB) mode in April-May and, finally, the Indian Ocean Dipole (IOD) averaged from September to November, also, both preceding $(\operatorname{IOD}(-1))$ and following the $\operatorname{ISM}(\operatorname{IOD}(0))$. The respective merits and associated dynamics of the selected indices are compared through various correlation and regression analyses.

Our first result is a deceptive one: the statistical relationships with the ISM rainfall at the continental and seasonal scales are modest and only barely significant, particularly for the IOD, IOB and Nino(-1) indices. However, a detailed analysis shows that statistical relationships with the ISM rainfall time series are statistically biased as the ISM rainfall seems to be shaped by much intraseasonal variability, linked in particular to the timing of the onset and withdrawal of the ISM. Surprisingly, analysis within the ISM season shows that Nino(-1), IOB and SEIO indices give rise to prospects of comparatively higher ISM previsibility for both the ISM onset and the amount of rainfall during the second half of the ISM season. The IOD seems to play only a secondary role. Moreover, our work shows that these indices are associated with distinct processes occurring within the Indian Ocean from late boreal winter or early spring onwards. The regression analyses also illustrate that these (local) mechanisms are dynamically and remotely linked to different phases of ENSO in the equatorial Pacific, a result which may have useful implications in terms of forecasting strategies since the choice of the better indices then hinges on the concurrent phasing of the ENSO cycle.

Keywords: Indian Summer Monsoon; Indian Ocean; ENSO; long-range predictability; oceanatmosphere interactions. 


\section{Introduction}

Almost three decades ago, Krishnamurti (1971) first demonstrated that the Asian summer monsoon is one of the most energetic features of the climate system and that latent heat release by monsoon rainfall plays an important role in forcing the global atmospheric circulation even at midlatitudes. During the months of June through September, the rainfall associated with the Asian summer monsoon provides the main source of fresh water for millions of people in the Indian subcontinent. Furthermore, the countries of South Asia are primarily based on agricultural economy, which is again closely linked to the monsoon rainfall (Pant and Rupa Kumar, 1997). Therefore, the prediction of Indian Summer Monsoon (ISM) rainfall is not only scientifically challenging but is also important for planning and devising agricultural strategies.

Though the probability of occurrence of a weak ISM during an El Niño event and that of a strong ISM during a La Niña event is large, El Niño-Southern Oscillation (ENSO) can explain only about 35\% variance of ISM rainfall (Webster et al., 1998). Moreover, the ISM-ENSO relationship has considerably weakened during recent decades (Kinter et al., 2002). Therefore it is natural to explore the possible influence of the neighboring Indian Ocean on ISM rainfall variability (Krishnan et. al., 2003; Krishnan and Swapna, 2009; Clarke et al., 2000; Terray et al., 2003, 2007; Yang et al., 2007; Izumo et al., 2008; Park et al., 2010; among many others).

The relationship between tropical Indian Ocean Sea Surface Temperature (SST) and ISM has been the subject of many observational studies before the end of the twentieth century (Shukla and Misra, 1977; Weare, 1979; Shukla, 1987; Joseph and Pillai, 1984; Rao and Goswami, 1988; Terray, 1995; Harzallah and Sadourny, 1997; Clarke et al., 2000). While several of these studies have found that some precursory SST signals exist before the ISM onset (Harzallah and Sadourny, 1997; Rao and Goswami, 1988; Nicholls, 1995; Clark et al., 2000; Sahai et al., 2003), others have found that it is very difficult to establish a clear relationship between Indian Ocean SSTs and ISM variability during the boreal summer (e.g. after the ISM onset). It is also fair to say that some of these earlier studies have obtained quite different and at times contradictory results. Indeed, based on these first studies (Shukla, 1987), many authors have suggested that tropical Indian Ocean SST may be considered as a passive element of the ISM system at the interannual time scale. 
On the other hand, recent studies also suggest the existence of coupled dynamics in the Indian Ocean, which may be partly independent of ENSO and give rise to strong interannual anomalies over the Indian Ocean.

The so-called Indian Ocean SST Zonal/Dipole mode (Saji et al., 1999; Webster et al. 1999; IOD hereafter), which peaks during boreal fall is one of such phenomena. The frequent occurrence of IOD events during the last two decades has generated considerable interest to probe the role of IOD in the coupled monsoon-ENSO system (Lau and Nath, 2004; Yamagata et al., 2004; Izumo et al., 2010). However, there is a lot of contradicting results in the literature on the cause and effect relationships, if any, between the two phenomena. First, a number of studies have suggested that the IOD may be a natural part of the Asian summer monsoon and the Tropospheric Biennial Oscillation (TBO, e.g. Meehl and Arblaster, 2002, 2003; Loschnigg et al., 2003, Li et al., 2006; Webster and Hoyos, 2010). Here, the IOD is argued to arise from the ocean-atmosphere interactions within the Indian Ocean with links to the Pacific involved with the TBO. In this framework, strong ISMs are followed by negative IOD events and strong Australian monsoons and negative IOD events precede both El Niño and weak ISMs (Meehl and Arblaster, 2003; Izumo et al., 2010; Webster and Hoyos, 2010). Another suggestion is that positive IOD events coincide with wet conditions over the Indian subcontinent (Behera et al. 1999; Ashok et al., 2001, 2004; Li et al. 2003; Gadgil et al., 2004; Swapna and Krishnan, 2008; Krishnan and Swapna, 2009). However, Li et al. (2003) argue that the strong ISM will then tend to damp the original IOD event while Swapna and Krishnan (2008) and Krishnan and Swapna (2009) suggest the opposite: the existence of positive feedbacks between positive IOD events and strong ISMs. Furthermore, Ashok et al. (2001, 2004) suggest that the influence of IOD on the ISM is opposite to the effect of ENSO, and that the IOD-monsoon rainfall relationship varies complementarily to that between ENSO and monsoon rainfall. Therefore, a better understanding of the linkages between ISM rainfall and IOD events will be a welcome contribution to the literature.

Another SST dipole mode in the southern Indian Ocean, seasonally phase-locked to the austral summer, has also been documented (Behera and Yamagata; 2001; Hermes and Reason, 2005; Chiodi and Harrison, 2007). Recent studies using observed data and coupled models have demonstrated that this Indian Ocean Subtropical Dipole (IOSD) mode plays a significant role in influencing the monsoon, IOD and ENSO (Fischer et al., 2005; Terray et al., 2003, 2005, 2007; Terray, 2010). More precisely, these works suggest that the IOSD 
events play a significant role in the variability of Indo-Pacific Tropical climate, and interact with ISM and ENSO after the so-called 1976-77 climate shift (Nitta and Yamada, 1989; Terray and Dominiak, 2005), highlighting the possible role of global warming or decadal variability on the interannual variability of the tropical climate. Consideration of this dipole may improve long-range forecasts of ISM rainfall (Terray et al., 2003) or ENSO (Dominiak and Terray, 2005; Terray, 2010).

The interannual SST anomalies in the Indian Ocean during boreal winter are largely due to the remote ENSO forcing through the atmospheric bridge mechanism (Lau and Nath, 2000, 2003; Alexander et al., 2002) or El Niño-induced westward-propagating oceanic Rossby waves in the South Indian Ocean (Xie et al., 2002). However, the existence of an intrinsic tropical Indian Ocean Basin (IOB) mode, maintained by local air-sea interactions during the spring and summer seasons following major El Niño events has also drawn great attention recently (Du et al., 2009; Xie et al., 2009). Since this basin-wide Indian Ocean warming persists well into the following boreal spring and summer, its influence on ISM variability has also been the focus of several recent studies (Annamalai et al., 2005; Yang et al., 2007, Park et al., 2010). However, the physical mechanisms which explain the links between ISM and IOB related SSTs are, as yet, not well understood and deserve further studies.

In summary, the relationships between the different modes of Indian Ocean coupled variability and their respective merits as far as the long-range predictability of the ISM is concerned have yet to be explored in a systematic manner from observational or modeling perspectives. This necessity is further recognized by the fact that these interannual modes interact in a complicated manner with both the Asian monsoon and ENSO. Thus, the primary goal of this study is to further investigate the spatiotemporal characteristics of Indian Ocean SSTs and its relationships with ISM, with a special focus on coupled modes of variability such as IOD, IOSD and IOB modes. Diagnostic analysis of observations is carried out, first to test the statistical significance of the relationships between ISM and these specific modes of Indian Ocean coupled variability and, secondly for elucidating the physical processes responsible for these statistical associations. In terms of long-range predictability of ISM, it is also important to clarify the lead-lag relationships among these various coupled modes and ENSO. This is a necessary step if we wish to demonstrate that these modes are useful for improving the long-range forecasting of the ISM beyond ENSO. 
This paper is organized as follows. Data and methods are described in Section 2. Using a simple correlation analysis, we first identify and describe the main statistical as sociations between the ISM rainfall, onset and withdrawal date time series and specific indices of IOD, IOSD and IOB modes in Section 3. We then turn to our main result, the relationships between the evolution of these coupled patterns of variability and ISM in Section 4. The conclusions and some discussions are given in Section 5.

\section{Data and statistical techniques}

\section{a. Datasets}

The monthly ISM rainfall is provided by the Indian Institute of Tropical Meteorology (IITM) through their website. This ISM rainfall monthly time series covers the period 1871-2005 and consists of an area-weighted average of 306 rain gauges distributed evenly across India (Parthasarathy et al., 1995).

The onset and withdrawal time series used in the correlation analyses cover the 1979-2005 period and are derived from objective definitions in relation to tropospheric seasonal warming (Xavier et al., 2007). More precisely, the ISM onset and withdrawal dates are estimated from the NCEP/NCAR reanalysis, based on the change of sign in the meridional gradient of upper tropospheric temperature (averaged between $700 \mathrm{hPa}$ and $200 \mathrm{hPa}$ ) between a northern box $\left(40^{\circ}-100^{\circ} \mathrm{E} ; 5^{\circ}-35^{\circ} \mathrm{N}\right)$ and a southern box $\left(40^{\circ}-100^{\circ} \mathrm{E} ; 15^{\circ} \mathrm{S}-5^{\circ} \mathrm{N}\right)$ over the Asian Monsoon region. For comparison, we have also used the dates of ISM onset as derived by the India Meteorology Department (IMD), although these dates are available to us over a shorter period from 1979 to 2001.

To complement the IITM rainfall time series, our analysis also makes use of Outgoing Longwave Radiation (OLR), which is a widely used indicator of convective precipitation in the Tropics. The OLR used here covers the period from 1979 to the present and is the interpolated OLR data provided by the National Oceanic and Atmospheric Administration Cooperative Institute for Research in Environmental Sciences (NOAA-CIRES; Liebmann and Smith, 1996). 
We use the NCEP-Department of Energy (DOE) Atmospheric Model Intercomparison Project (AMIP-II) reanalysis (Kanamitsu et al., 2002, hereinafter NCEP2) to examine the ISM atmospheric circulation. The period analyzed runs from January 1979 to December 2005. Although data exist over a longer period for the previous NCEP-NCAR reanalysis (Kalnay et al., 1996), we choose to use only the second NCEP reanalysis, since it is considered as more reliable for at least two reasons: first, many of the known problems found in the earlier reanalysis have been corrected and, secondly, use is made of satellite data for the whole period (possible shifts due to their use or not are therefore avoided).

The observed SST dataset selected for the study is the Hadley Centre sea ice and sea surface temperature dataset (HadISST1.1) developed by Rayner et al. (2003). Using a unique combination of monthly globally complete fields of SST on a $1^{\circ}$ latitude-longitude gridded mesh and improved bias corrections, quality of HadISST1.1 has been found to compare well with other historical SST analyses (Rayner et al. 2003). Due to uncertainties in the first part of the record and to be consistent with the NCEP2 and OLR datasets, we have used only the period from 1979 to the present as a basis for our correlation analyses in the following sections. However, the full SST record is used to remove the long-term trends of Indian Ocean SSTs before further statistical analyses (see below).

SST and atmospheric fields are linked with each other through processes at the air-sea interface like surface turbulent and radiative fluxes. The surface heat fluxes analyzed here are derived from products of the objectively analyzed air-sea fluxes (OAFlux) for the Global Oceans project (Yu et al., 2008) and are obtained from the Woods Hole Oceanographic Institute through ftp://ftp.whoi.edu/pub/science/oaflux/data. These fluxes are used to identify the processes that are important for the generation or attenuation of SST anomalies in the Indian Ocean.

The Simple Ocean Data Assimilation (SODA) product (Carton and Giese, 2008; Version 2.023) is also used in this study, in particular to follow the evolution of heat content in the first 130m layer of the Indian Ocean, during the 1979-2004 period. SODA is available at $0.45^{\circ} \times 1^{\circ}$ latitude-longitude resolution in the Tropics, and has 20 vertical levels with $15-\mathrm{m}$ resolution near the surface. 
Finally, the coupled modes examined here (namely ENSO, IOD, IOSD and IOB) will be represented by SST indices, defined as SST anomalies averaged over various regions and during specific seasons. Each index is based on a specific criterion taken from the literature (see Table 1). Note that this analysis considers two different Nino indices, Nino(-1) and Nino(0), which both peak during boreal winter but one index $(\operatorname{Nino}(-1))$ preceeds while the other (Nino(0)) follows the ISM. The denominations (0) and (-1) thus refer to the ISM season rather than the evolution of the ENSO event itself. Based on recent findings (Izumo et al., 2010; Webster and Hoyos, 2010) and the same index denomination as for ENSO, the IOD index is also defined during the boreal fall, both preceding and following the ISM (IOD(-1) and $\operatorname{IOD}(0)$ hereafter). Finally, we have decided to limit our analysis of the IOSD to its variability in the South East Indian Ocean in agreement with the results of Terray et al. (2003, 2005 and 2007) and Terray and Dominiak (2005).

\section{b. Statistical methods}

SST variations in the Indian Ocean occur over a wide range of time scales (Schott et al., 2009). In particular, analysis of long-term time series shows that the monthly tropical Indian Ocean SST has experienced an average warming trend of $0.01^{\circ} \mathrm{C}$ yr- 1 since 1945 (Nitta and Yamada, 1989; Terray, 1994) with a significant 0.3 or $0.5^{\circ} \mathrm{C}$ shift to a warmer state that occurred around 1976-1977 (Clark et al., 2000; Terray and Dominiak, 2005). This gradual, but significant warming of the Indian Ocean may be largely attributed to the global warming as many of the historical simulations using the IPCC coupled climate models also indicate a substantial warming of the Indian Ocean in response to increasing greenhouse gases during the recent decades (Alory et al., 2007). However, similar low-frequency fluctuations are absent in the observed all-India rainfall time series as well as in the all-India rainfall time series computed from the recent IPCC coupled simulations (Rupa Kumar et al., 2002). In light of these results, it is clear that the trend in Indian Ocean SSTs is probably detracting from the relationship between interannual variations of ISM rainfall and Indian Ocean SSTs. More precisely, the existence of a non-stationary, externally forced, component of SST Indian Ocean variability may be masking the Indian Ocean SST-ISM rainfall relationships at the interannual time scale since observed SST anomalies over the Indian Ocean are relatively small (Schott et al., 2009).

It is, thus, important to eliminate the influence of this Indian Ocean warming trend before 
addressing the problem of Indian Ocean SSTs-ISM relationships at the interannual time scale. To achieve this goal, the annual cycle, trend and very low-frequency variations were removed from the historical SST monthly fields using the STL (Seasonal-Trend decomposition procedure based on Loess) additive scheme developed by Cleveland et al. (1990). The STL procedure is a powerful statistical technique for describing a discrete time series (Cleveland et al., 1990). In the STL procedure, the analyzed $X_{t}$ monthly time series is decomposed into three terms:

$$
X_{t}=T_{t}+A_{t}+R_{t}
$$

The $T_{t}$ term is used to quantify the trend and low-frequency variations in the time series. The $A_{t}$ term describes the annual cycle and its modulation through time, while the $R_{t}$ term is the remaining variation in the data beyond the annual and trend components. The STL procedure is particularly useful for extracting the interannual signal from non-stationary and noisy climate observations, as illustrated by Cleveland et al. (1990) or Terray (2010). The interannual SST monthly anomalies analyzed here are obtained as the departures from the extracted seasonal cycle, $A_{t}$, and trend, $T_{t}$, components estimated by the STL procedure for each grid-point time series in the SST datasets from 1979 to 2007.

Standard regression and correlation analyses are used to describe the life cycle of coupled patterns of variability in the Indo-Pacific areas. Note that none of the fields used in these regression exercises have been filtered by the STL procedure in order to give an exact overview of the long-range predictability associated with our key indices. To account for the effects of autocorrelation, the statistical significance levels for the correlation and regression coefficients are estimated using the method proposed by Ebisuzaki (1997) with 999 samples.

\section{Relationship between ISM rainfall and Indo-Pacific SST indices}

The aim of this part is to assess the potential predictability of ISM rainfall provided by the key SST indices defined in the previous section. The statistical relationships, based on correlation analyses, are examined over the 1979-2007 period and are summarized in Table 2. 
During the conventional June to September (JJAS) season, the ISM rainfall is significantly correlated with the SEIO and Nino(0) indices, whereas results are generally weak and poorly significant with other indices. Table 2 is able to capture some well-known features of the ENSO-ISM relationship, as the ISM rainfall is out-of-phase with the development phase of ENSO in the Pacific (correlation of -0.4 with Nino(0) index) and in-phase with its mature and decaying phases (correlation of 0.18 with Nino(-1) index). In spite of recent findings (see Introduction) which show a weakening of the ISM-ENSO relationship during recent decades, the best result at the seasonal time scale is here obtained with the Nino(0) index. Meanwhile, seasonal correlations also fail to reproduce the known merits of the Nino(-1), IOB and IOD indices for the seasonal prediction of ISM rainfall suggested by recent studies (Yang et al., 2007; Krishnan and Swapna, 2009; Webster and Hoyos, 2010). This apparent weak seasonal previsibility may be related to the subseasonal ISM variability and draws on the need to examine these relationships at shorter timescales. To this end, we have completed these seasonal analyses by monthly correlations between each index and ISM rainfall (Table 2). We have also computed correlation coefficients between SST indices and the ISM onset and withdrawal dates time series (Table 3), as ISM onset and withdrawal dates are important aspects of ISM variability which contribute to make each monsoon unique and have a significant practical value (Ramesh Kumar et al., 2008). The timing of the onset and withdrawal are particularly important as they statistically influence the amount of rainfall during the early and late monsoon seasons as we will illustrate below. Understanding the influence of each index on these specific components of ISM intraseasonal variability thus becomes a key element to the more global assessment of predictive relationships with the ISM.

Surprisingly, our analysis (Tables 2 and 3) shows the importance of Nino(-1) and IOB indices for the ISM onset phase. More precisely, the IOB and Nino(-1) indices are, on one hand, significantly and negatively correlated to the June ISM rainfall (correlations of -0.32 and 0.46, respectively, in Table 2) and, on the other hand, significantly and positively correlated with the ISM onset dates (correlations of 0.47 and 0.63 , respectively, in Table 3). The ISM onset thus tends to be significantly delayed during the decaying El Niño years. These robust results are consistent with earlier studies which have recorded a one-week delay of the ISM onset following the mature phase of El Niño events and its subsequent Indian Ocean warming (Joseph et al., 1994; Annamalai et al., 2005). Moreover, this leads to the hypothesis that the delayed ISM onset is partly responsible for the negative correlations of the IOB and Nino(-1) 
indices with ISM rainfall in June. The statistically significant and negative correlation (-0.4) between the June ISM rainfall and the ISM onset dates is in agreement with this suggestion. In other words, the rainfall over the Indian subcontinent is reduced in June after the mature phase of El Niño, mainly because of the delayed onset and not necessarily because the monsoon circulation is weak after the onset. On the other hand, correlations of SEIO, Nino(0) and IOD (0 or -1$)$ indices with ISM rainfall in June (see Table 2$)$ or the onset date (see Table 3) are weak and insignificant. This suggests no significant impact of El Niño, during its development phase, or IOD, during the preceding year, on ISM onset. However, we will illustrate below that ENSO, during its development phase, has a larger influence on the withdrawal of the monsoon.

We next focus on the evolution of the statistical relationships within JJAS. Despite weak and poorly significant values during mid ISM season, results of the IOB, Nino(-1), IOD(-1) and SEIO indices in Table 2 are characterized by a steady increase in the amplitude of correlations from July to September. This low-frequency evolution is not as clear for the other indices, as correlation values remain weak for the $\operatorname{IOD}(0)$ index throughout the season, and fluctuate from one month to another with the Nino(0) index. Statistics linked to these two indices are overall difficult to interpret. The ISM-Nino(0) relationship, in particular, seems to be modulated by important intra-seasonal activity, a fact which may even control its global nature over the JJAS season. Nevertheless, in September, correlations between ISM rainfall and the SST indices are generally enhanced. Indeed, results are statistically significant for nearly all indices (excepted the $\operatorname{IOD}(0)$ index), with maximum values obtained for the SEIO and $\operatorname{Nino}(0)$ indices $(0.56$ and -0.52 , respectively). Note that, September rainfall is also strongly linked to ISM withdrawal dates ( 0.71 correlation), which, in turn, is significantly associated with both SEIO and Nino(0) indices (correlations of 0.63 and -0.55 , respectively). Therefore, in an analogous way as during the onset phase, the positive (negative) correlation value obtained with ISM rainfall in September may be explained by SEIO's (Nino(0)'s) tendency to postpone (advance) the withdrawal of the monsoon. It is also interesting to observe here that this statistical association is the strongest with the SEIO index.

These preliminary results show that monthly statistics are significantly influenced by the timing of the onset (withdrawal) of the monsoon rains, particularly in June (September), and that this could account for the generally negative (positive) correlations obtained during the early (late) part of the ISM season. This temporal dichotomy within the ISM season had 
already been observed by Terray (1995), Ailikun and Yasunari (2001), Terray et al. (2003) and Park et al. (2010). It is also clearly illustrated here by Figure 1, which shows the lead-lag correlations between all the key SST indices and ISM rainfall taken separately in June-July (JJ) and August-September (AS). Note that, for this analysis exclusively, the SST indices are not only considered during their specific peaking season (as defined in the previous section) but throughout the years preceding and following the monsoon. Figure 1 is therefore presented as an alternative approach to our first analysis, and helps highlight the statistical dichotomy between the early and late summer season.

Indeed, Figure 1a illustrates once again a globally poor statistical association of ISM rainfall in JJ with all indices. The only significant correlation coefficient is obtained with the Nino time series in April-May, just before the monsoon onset (significant value of -0.39). Note that this spring Nino index, which probably combines the effects of both early developing and slowly decaying El Nino's events, is also influencing the ISM onset (correlation of 0.56 with onset dates). However, by AS predictability is enhanced (Fig. 1b), with important precursory signals for ISM rainfall in the preceding winter and spring. The maximum correlation values are obtained in DJ with Nino, in FM with IOB and AM with SEIO, which are quite consistent with the definitions of each index found in literature. The IOD index seems to have continuously weaker correlations with ISM rainfall, suggesting it could only play a secondary role in comparison to other indices for the ISM prediction.

In conclusion, this first analysis has shed a light on the importance of subseasonal features, such as the timing of ISM onset and withdrawal, in the assessment of predictive relationships with ISM rainfall. The monthly correlations in Table 2 and Figure 1 illustrate the temporal dichotomy often observed within the ISM season in the literature, as well as the existence of low-frequency variations inside the ISM season as mentionned before (Buermann et al., 2005; Park et al., 2010; Terray et al., 1995). This analysis has also suggested a parallel between the Nino(-1) and IOB indices during the earlier part of the season, and between the Nino(0) and SEIO indices in the later part. However, all these results need now to be interpreted on a more physical basis. For instance, we need to understand which physical processes explain the similarities between Nino(-1) and IOB or Nino(0) and SEIO indices. What are the physical roots of the temporal evolution of the correlations between SST indices and the ISM rainfall within the JJAS season? We also need to know if and how distinct indices, such as the IOB, Nino(-1) and SEIO, can offer complementary potential ISM predictability (since they have 
correlation values which peak with a comparable amplitude, and during approximately the same period). The answer to these questions requires a closer examination of the dynamics associated with the Nino, IOB and SEIO indices.

\section{Dynamics associated with each index during the ISM season}

The aim of this section is thus to investigate the mechanisms that govern the evolution of these coupled modes of variability in relation to the ISM seasonal march. Note, however, that we have eliminated the IOD index from this analysis, given its statistically weaker association with ISM rainfall (e.g. Section 3). As a result, the analysis will focus on the dynamics associated with the Nino(-1), Nino(0), IOB and SEIO indices and their low-frequency evolution before and during the development of the ISM season.

\section{a) Nino(-1) and IOB indices}

We examine first the mechanisms associated with the Nino(-1) and IOB indices. Bimonthly SST regression patterns onto these two indices are shown in Figure 2, and present remarkably similar evolutions from February-March (FM) to August-September (AS). This striking resemblance is also captured by the regression with other variables (not shown), and thereby corroborates the parallel which was previously suggested between both indices in Section 3, but illustrated here from winter to the end of the following summer. Therefore, based on this robust analogy and the premise of an earlier ISM forecast with the Niño34 index in the preceding winter, we will focus on the regression patterns associated with the Nino(-1) index.

The distribution of SST anomalies from FM to June-July (JJ) is marked by strong positive SST anomalies in the central and eastern Pacific Ocean, which are out of phase with anomalies in the west part of the basin, consistent with the decaying phase of an El Niño event (Fig. 2). Meanwhile, the tropical Indian Ocean is characterized by a significant warming which persists well into the ISM season when SST anomalies in the central Pacific have almost completely faded away (Yang et al., 2007; Li et al., 2008; Du et al., 2009; Schott et al., 2009). Interestingly, Figure 2 suggests a stronger warming in the southwest and equatorial Indian Ocean from FM to AM, consistent with the significant positive heat content anomalies found in this region and associated with the Nino(-1) index during spring in Figure 
3a. It has already been shown that the ENSO-induced atmospheric changes in the West Pacific during boreal fall and winter force slow downwelling Rossby waves to propagate in the Indian Ocean, which deepen the thermocline and raise SST specifically in the South-West Indian Ocean (SWIO), a region where the mean thermocline is shallow (Xie et al., 2002; Schott et al., 2009). On the other hand, the equatorial heat content anomalies probably stem from the changes in the Indo-Pacific Walker circulation occurring, this time, during the mature phase of El Niño. Indeed, the modulated Indian Walker cell and the well-organized subtropical Northwest Pacific anticyclone favor anomalous low-level easterlies in the equatorial Indian Ocean (Fig. 3b), which weaken the seasonal westerly Wyrtki jet and thus help maintain warm waters in the western part of the basin until boreal spring (Fig. 3a). This lagged SST response to ENSO has already been well documented (Klein et al., 1999; Reason et al., 2000; Alexander et al., 2002; Lau and Nath 2003; Xie et al., 2002; Huang and Kinter 2002; Wang et al., 2003; Annamalai et al., 2005). Our analysis is in line with these works and further shows that the warm SST anomalies in the south Indian Ocean are dominant and robust features of the Indian Ocean variability in the late boreal spring following an El Niño event.

Interestingly, by AM, the SWIO warming is collocated with intense local convection (shown by negative OLR anomalies in Fig. 4a) and incites the convergence of northerly winds onto this region (Fig. 3b). The induced low-level flow is, however, influenced by the Coriolis force when crossing the equator, which leads to the "C-shaped" wind pattern observed in Fig. 3b, with northeasterly (northwesterly) wind anomalies north (south) of the equator. By suppressing evaporation south and north of the equator (not shown), this wind pattern is then able to sustain the initial warm SST anomalies in the south Indian Ocean and allows the northward propagation of the warm SST anomalies, a process partly consistent with a positive Wind-Evaporation-SST (WES) feedback. At the same time, convective activity is largely decreased north of the equator from the Arabian Sea to the Northwest Pacific suggesting a remote forcing from the subtropical Northwest Pacific anticyclone (see Figs. 3b and 4a). Previous works have already recognized the presence of this asymmetric atmospheric pattern during boreal spring over the tropical Indian Ocean (Kawamura et al., 2001; Wu et al., 2008; Du et al., 2009). Altogether, Figures 3 and 4 confirm that the asymmetric atmospheric pattern tends to occur during the decaying phase of El Niño and is able to persist through early summer induced by the SWIO warming and possibly anchored by the subtropical Northwest Pacific anticyclone. 
Nevertheless, we must bear in mind that traditionally at this time of the year (e.g. in AM), the monsoon is preparing to set in over India. Climatology conditions over the Indian Ocean are thus typical of this pre-onset phase, with the warmest area of the Indian Ocean lying in the Arabian Sea. Indeed, this region of high SST can usually cause large-scale moisture convergence, leading to the local build-up of deep convection, with a heating of the tropospheric column, a lowering of the surface pressure and a strengthening of low-level westerly winds, giving rise to a local Hadley circulation over the western Indian Ocean (Joseph et al., 2003). The ISM onset date is directly linked to the timing of this deep convection and the setup of this local Hadley cell: therefore the earlier the SST peak in the Arabian Sea, the earlier the monsoon onset (Soman et al., 1993; Joseph et al., 1994 and Ramesh Kumar et al., 2008). However, in the spring following an El Niño event, a strongest warming is located south of the equator in the SWIO (Fig. 2). The increased SST, decreased OLR and SLP in this region can reduce the strength or even induce a reversal of the local Hadley cell over the western Indian Ocean in AM as illustrated by cross-equatorial northerly (southerly) wind anomalies at $850 \mathrm{hPa}(200 \mathrm{hPa})$ in this region (see Figs. 3b-c). Consistent with the work of Joseph et al. (2003) and Annamalai et al. (2005), this anomalous cell suppresses convection over the Arabian Sea and maintains the convective activity in the south, causing a delayed northward migration of the InterTropical Convergence Zone (ITCZ) and a late ISM onset. Consequently, the asymmetric atmospheric mode observed in AM over the tropical Indian Ocean after an El Niño presents unfavourable conditions for the ISM onset. Note that this ISM pre-onset phase may also be influenced by larger-scale features, such as the substantial warming of the troposphere often associated with an El Niño (Chiang and Sobel, 2002; He et al., 2003 among others). As illustrated in Figure 3d, these warm tropospheric temperature anomalies are able to persist from winter to the following spring and spread across the entire tropical belt (between $20^{\circ} \mathrm{S}-20^{\circ} \mathrm{N}$ ). Moreover, negative temperature anomalies associated with Nino(-1) have set up over North India by AM. This leads to the establishment of a significant meridional gradient between $15^{\circ} \mathrm{S}-35^{\circ} \mathrm{N}$, a large-scale tropospheric feature which is reminiscent of Goswami and Xavier's (2006) definition of ISM onset (see Section 2a). Therefore, by setting up persistent negative (positive) anomalies over North (South) India in the following spring, an El Niño creates unfavorable conditions for the reversal of the tropospheric temperature gradient over the monsoon region which delays the subsequent ISM onset. 
Altogether, these results thus corroborate the negative correlation obtained in Table 3 between the Nino(-1) and IOB indices and the ISM onset dates.

In May-June, the anomalous patterns are consistent with this delayed ISM onset (Figs. 4 and 5). Indeed, the "C-shaped" wind anomalies at $850 \mathrm{hPa}$ in the western Indian Ocean (Fig. 5a) indicate a deceleration of the cross-equatorial low-level jet stream (LLJ) (Findlater 1969; Joseph and Sijikumar 2004), and a delay in the ensuing moisture transport, which is usually known to maintain the monsoon over the Indian subcontinent once it gets established. Meanwhile, the subsident branch of the anomalous reversed Hadley cell over the south Arabian Sea is associated with a cloudless sky, reduced upwelling and evaporation along the African coast (consistent with short wave and latent heat fluxes not shown) and induces a significant warming of the south Arabian Sea (Fig. 2c). This anomalous warming is subsequently collocated (in June) with a low pressure anomaly and cyclonic cell at $850 \mathrm{hPa}$ (Fig. 5b) as well as increased wind speed and evaporation just to the north of the equator (Figs. 6a and d), which suggests it may enhance in situ convection over the south Arabian Sea and thus cause the northward shift observed in OLR anomalies from the SWIO in May to the south Arabian Sea in June (Figs. 4a-b). This shift in convection marks the collapse of the asymmetric atmospheric pattern, the onset of the monsoon over the ocean, but also causes a delay in the ISM onset over India, since convection at this time is favoured over its adjacent oceanic regions. The positive OLR anomalies prevailing over the Indian subcontinent in June (Fig. 4b) are consistent with this hypothesis, and may also account for the negative correlation obtained between the Nino(-1) and ISMR in June in Table 2.

From June onwards, the evolution of OLR anomalies shows a quite distinctive northeastward propagation from the Arabian Sea to the Indian subcontinent (Fig. 4). Indeed, after being maintained for a significant time over the south Arabian Sea, significant negative convection anomalies are able to reach the west coast of India later in the season, in August, and spread over the entire subcontinent by September. Although this evolution of convective activity during the ISM season is not yet fully understood, our observational analysis points towards a possible interaction with both local and remote dynamical coupling processes associated to the end of an El Niño. The processes we suggest below may also help understand the gradual increase in correlations with ISM rainfall from June to September in Table 2. 
Our first hypothesis is based on the existence of a local feedback between convection and temperature anomalies in the Indian areas. The preceding analysis suggests that while convection is favored over the south Arabian Sea in the early ISM season, SST tends to cool from June to July (see Fig. 7). Indeed, by July, the SST has returned to climatology and the cyclonic wind anomalies have disappeared (Fig. 5c). This result is consistent with the observed rebound to climatological winds noted in Park et al. (2010). Meanwhile, Figure 7 also indicates a significant rise from June to July in $2 \mathrm{~m}$ air temperatures over India, thereby sustaining the thermal contrast between land and ocean. This suggests that, from June to September, the low-frequency northeastward propagation of the convection anomalies in the Indian region is thus partly driven by the modulated temperature gradient from the south Arabian Sea towards the Indian subcontinent, by processes similar to those governing the propagation of rainfall over the land during the onset of the monsoon (Webster et al., 1998).

Our second hypothesis is based on the possible remote influence of the Northwest Pacific region on the development of the ISM. In our analysis, this region stands out as a statistically prominent feature of the decay of an El Niño, characterized by robust positive OLR anomalies (see Fig. 4), collocated in July and August with a highly significant positive SLP anomaly and a vigorous low-level anticyclonic anomalous wind pattern (Figs. 5c-d). The origin and persistence of this anticyclone have often been linked to ENSO and its subsequent warming in the tropical Indian Ocean. In particular, Xie et al. (2009) explain that this warming excites a warm atmospheric Kelvin wave, which propagates into the western Pacific along the equator. The consecutive decrease in equatorial SLP drives northeasterly wind anomalies, induces surface wind divergence and suppresses convection over the subtropical Northwest Pacific. In our analysis, an interesting out-of-phase relationship in convection is observed between the Northwest Pacific and the Indian Ocean during the ISM season. Indeed, Figure 4 shows that while the convective cell is maintained over the Arabian Sea, from June to August, convection is simultaneously suppressed over the Northwest Pacific Ocean, suggesting that the anomalous Northwest Pacific anticyclone may also play an important role in the transitory blocking of convection over the Arabian Sea during early boreal summer. The low-level wind and pressure anomalies during this period seem consistent with this hypothesis (Fig. 5). Indeed, Figure 5c shows that, by July, the northeasterly wind anomalies have disappeared over the Arabian Sea, allowing for the moist-laden monsoonal winds to develop and strengthen from this region to the west coast of India. Meanwhile, the circulation over the Bay of Bengal seems to be significantly influenced by the strengthening and eastward extension of 
the anomalous Northwest Pacific anticyclone. Easterly wind anomalies originating from the southern branch of the anomalous anticyclone, are seen to penetrate into the Bay of Bengal and even extend to the west coast of India by August. During July and August, the local reduction in wind speed and evaporation associated with the suppressed convection over the eastern Indian region north of the equator (Figs. 6b-c and 6e-f), are in opposition with the concurrent build-up of moist air and upward motions over the Arabian Sea where the wind is near climatology. In other words, we here suggest that the weakening of the monsoon winds in the eastern Indian region (north of the equator) associated with the Northwest Pacific anticyclone may also play a significant role in sustaining the convection over the Arabian Sea during July and August by dynamically strengthening upward motions. The OLR anomalies associated with a Northwest Pacific summer monsoon dynamical index, as defined in Wang et al (2001), agree with this suggestion as significant negative anomalies are seen to prevail over the Arabian Sea, indicating the blocking of local convection during July-August (Fig. 8). Note also that, consistently with this hypothesis, the disappearance of the anomalous Northwest Pacific anticyclone in September coincides with the unlocking of convection over the Arabian Sea and its propagation over the Indian subcontinent in the Nino(-1)/OLR regression patterns (Fig. 4e).

\section{b) Nino(0) and SEIO indices}

Anomalous fields regressed onto the Nino(0) and SEIO indices generally display very similar evolutions during the ISM. Figure 9, in particular, illustrates how SST anomalies regressed onto the SEIO index are opposite in sign but comparable in amplitude and pattern with those associated with $\mathrm{Nino}(0)$, and this more specifically in $\mathrm{JJ}$ and AS. This resemblance is also in good agreement with previous works, which have recognized the SEIO index as a significant precursor of ENSO after the 1976-77 climate shift (Terray et al., 2005; Terray and Dominak, 2005; Dominak and Terray, 2005; Terray, 2010). Given the general acknowledgment of an inverse ENSO-ISM relationship corroborated by the results in Table 2, even for the period after the 1976-77 climate shift, it may thus be eligibly inferred that the SEIO index is first linked to the ISM via its forcing on ENSO. However, the coupled experiments of Terray et al. (2007) have also demonstrated that SEIO SSTs in FM are able to significantly influence the ISM, regardless of the concurrent ENSO state in the Pacific: this suggests that local processes within the Indian Ocean may also be playing an important role before and during the ISM season. Our correlation analysis in Section 3 stands in line with this hypothesis, as it 
distinguishes the SEIO and Nino(0) indices in their relationship with the ISM, by showing that the monthly correlations associated with $\operatorname{Nino}(0)$ are quite chaotic, in contrast with the steady strengthening of the SEIO-ISM relationship from June to September (see Table 2). Therefore, given the long-range ISM forecast offered by the SEIO in FM and the apparently higher robustness of the SEIO-ISM relationship, we will focus on the regressions with the SEIO index and examine the local dynamical processes through which it may impact the ISM rainfall and atmospheric circulation.

The distribution of SST anomalies in Figure 9e shows that in FM, the SEIO index is significantly linked to a decaying El Niño event in the equatorial Pacific Ocean and to an anomalous subtropical SST gradient in the south Indian Ocean. Previous studies have shown that such subtropical dipole events are generated by Mascarene high pulses during boreal winter, and can occur independently from ENSO, producing significant climate anomalies in southern Africa (Behera and Yamagata, 2001, Reason et al., 2002), and over the entire IndoPacific region (Terray et al. 2005; Terray and Dominiak 2005; Terray, 2010). In FM, this anomalous dipole is located between $20^{\circ} \mathrm{S}$ and $40^{\circ} \mathrm{S}$ in the Indian Ocean, and is seen to persist until the end of the ISM season (Figs. 9e-h).

During boreal spring, the SST patterns show a decay of this anomalous dipole in the south Indian Ocean (Fig. 9f). However, the warm anomalies in the SEIO are still significant and have shifted northward, suggesting that ocean-atmosphere feedbacks may be operating at this time to allow the persistence of these SST anomalies (from FM to AM). The atmospheric response to the SEIO index in AM is consistent with this hypothesis and shows that the anomalous SST gradient in the south Indian Ocean forces the low-level flow to converge towards the anomalously warm region (Fig. 10). In Figs. 10a-b, negative OLR and cyclonic wind anomalies are consistently collocated with the warm anomaly in the SEIO, as opposed to the positive OLR anomaly and anomalous anticyclonic cell over the cooler southwest Indian Ocean region, a pattern consistent with an ocean-to-atmosphere forcing. At this stage, the northwesterly wind anomalies, observed on the eastern flank of the SEIO cyclonic circulation, tend to reduce the seasonal wind speed (Figs. 10b and d) and suppress local evaporation (Fig. 10c), which, in turn, sustains the initial warm anomaly and allows its northward propagation. On the other hand, wind anomalies on the western side of the SEIO convective perturbation strengthen the southeasterly trade winds (Fig. 10d). The increased wind speed is this time collocated with upward latent heat fluxes in the central part of the 
south Indian Ocean (Fig 10c), suggesting a cooling of SST anomalies via enhanced evaporation. As a result, the SST gradients are maintained in the south Indian Ocean and these gradients favour again the atmospheric convergence over the initial warm anomaly, a process consistent with a positive WES feedback. During the same period, convection is increased just over the warm SST anomaly, and along a latitudinal band between $5^{\circ} \mathrm{S}$ and $15^{\circ} \mathrm{S}$, which thus affects the seasonal position of the ITCZ (Fig. 10a). The increased cloudiness over this region is associated with upward short wave flux anomalies and a subsequent cooling of surface temperatures while the reversed processes are operating to the south (figures not shown). Hence, surface shortwave radiation anomalies associated with the SEIO index provides, by contrast, a negative feedback on SST anomalies during spring.

By June, there is a generally weak response to the SEIO index over the Indian Ocean. SST anomalies have lost statistical significance in the south Indian Ocean, suggesting that, at this stage, the negative feedback provided by the short wave radiation is more active and has significantly damped the SST fluctuations. Although the SEIO index has an overall weak impact on the ISM onset (see also Table 3), it seems able to trigger a significant atmospheric response in the eastern part of the Indian Ocean basin. Indeed, strong convective anomalies are observed over the Maritime Continent and eastern Indian Ocean (Fig. 11a), collocated with reduced wind speed near the west coast of Sumatra (Fig. 12a), an area which is usually shaped by intense coastal upwelling (Schott et al., 2009). Surface latent heat flux anomalies are not significant or are even of the wrong sign to sustain the warm SST anomaly in this region (Fig. 12e). This supports the idea that ocean dynamics may play a crucial role in the maintenance of warm anomalies at this particular time. Indeed, the northwesterly wind anomalies along the west coast of Sumatra can reduce the upwelling of cooler and deeper water, and subsequently lead to warmer SST and enhanced convection (Fischer et al., 2005; Terray et al., 2007). In line with Terray et al (2007), our results thus suggest that a coastal upwelling feedback is triggered along the west coast of Sumatra in June, a process which could explain why both the SST and atmospheric anomalies then reinvigorate and gain large significance during summer (Fig. 11).

From July to September, the anomalous patterns associated with the SEIO index are consistent with the development of this coastal upwelling feedback. Indeed, while latent heat flux anomalies remain weakly significant (Figs. 12f-h), the negative wind speed anomalies are maintained (Figs. 12b-d) and anchor the positive SST anomalies along the west coast of 
Sumatra (Figs. 9g-h). The atmospheric response to these anomalies is characterized, from June onwards, by the persistence and amplification of convective anomalies over the Maritime Continent and the southeast equatorial Indian Ocean (Fig. 11). In parallel, significant negative OLR anomalies are also observed in July over the Arabian Sea, and these anomalies propagate northeastwards to reach the Indian subcontinent by the end of the summer: a low-frequency evolution that matches the gradual increase in correlation obtained between the ISMR and SEIO indices (Table 2). Note that this evolution of convective anomalies over the Arabian Sea is also reminiscent of previous observations with the Nino(-1) index (see Fig. 4), although we will show here that they stem from distinct dynamical processes.

Indeed, the regression analyses with the SEIO index suggest that convection over the Arabian Sea and the ensuing ISM rainfall response, are not directly linked to local processes in the north Indian Ocean, but may instead result from fluctuations in atmospheric moisture transport in the south Indian Ocean. To begin with, the anomalous patterns in July indicate that the positive WES feedback is reinvigorated in the central part of the south Indian Ocean. The increased wind speed over this region (Fig. 12b) is consistently collocated with upward latent heat flux (Fig. 12f) and a subsequent cooler SST anomaly (Fig. 9g). This enhances the amount of humidity available over the southern Indian Ocean, although the dynamical response to the SEIO index over the Arabian Sea is rather weak at this stage (Fig. 12b). Our results are thus consistent with Terray et al (2007) and suggest that the appearance of negative OLR anomalies in the Arabian Sea in July (Fig. 11b) may result from the anomalous moisture transport from the south Indian Ocean via climatological winds.

From July onwards, the anomalous cyclone over the SEIO is amplified while it propagates northward (figure not shown). Once it reaches the equator in August, the northwesterly wind anomalies can trigger a Wind-Thermocline-SST feedback (Terray et al., 2007). This marks also the beginning of a dynamical response to the SEIO index in the north Indian Ocean, and the strengthening of interhemispheric winds (Fig. 12c). The ensuing feedback between the ISM circulation and the interhemispheric moisture transport may then eligibly account for the amplification of the OLR signal observed over the Arabian Sea and the increase in ISM rainfall during the late ISM season (Figs. 11c-d). 
Note that the SEIO index is also significantly related to the variability in the Northwest Pacific region during the months of July and August (Figs. 11 and 12). The observed patterns are remarkably similar to those associated with the Nino(-1), and are probably just a reflexion of the strong relationship between ENSO and SEIO indices. Indeed, the SEIO index used in this study is defined over a quite large geographical domain, which we suspect would embody both tropical (e.g ENSO) and extra-tropical influences (e.g subtropical Indian dipole) regarding ISM interannual variability.

\section{Conclusions and discussion}

This study has examined the variability and predictability of ISM rainfall at interannual timescales, by exploring its relationship with ENSO and various modes of Indian Ocean coupled variability. Several different SST indices are computed using observational data over the 1979-2007 period, and their respective merits are compared through correlation and regression analyses with ISM rainfall.

Our first result is a deceptive one and points towards a generally weak relationship between most of the indices and seasonal mean ISM rainfall. However, correlation analysis on a shorter timescale shows that seasonal mean values are statistically biased as the ISM season is shaped by important subseasonal variability, linked, in particular, to the onset and withdrawal dates of the monsoon (in June and September). Surprisingly, the monthly correlation values increase steadily and significantly during the summer season, and give rise to prospects of higher ISM previsibility with ENSO, IOB and SEIO indices for both the onset of the monsoon and the amount of rainfall during the second half of the monsoon season. In contrast, the relationship between the IOD index and ISM rainfall remains weak throughout the season: this result depreciates the IOD's forecast skills for the 1979-2007 period in comparison with the other SST indices.

A regression analysis is then carried out with the four remaining indices (namely IOB, Nino(1), SEIO and Nino(0) indices) in order to elucidate the physical processes responsible for these significant predictive relationships and understand their gradual increase during the boreal summer. Results show that distinct local processes occurring within the Indian Ocean 
can significantly impact the ISM rainfall and are responsible for the low-frequency evolution of the observed correlations.

First, the stepwise evolution of monthly SST, OLR and wind anomalies associated with the end of an El Niño event helps understand the steady increase in monthly correlations obtained between the ISMR and Nino(-1) or IOB indices documented in Table 2. The weak and negative correlation values in the early ISM season following an El Niño, can be due to a late ISM onset, followed by the development of convection in priority over a warmer south Arabian Sea. The gradual increase in correlation then matches the low-frequency northeastward propagation of convection from the south Arabian Sea to the Indian subcontinent during the monsoon season. Several factors may contribute to the maintenance of convection over the south Arabian Sea from June to August and its subsequent northward propagation: such as local feedbacks or a possible interaction with wind anomalies originating from the Northwest Pacific region.

Secondly, the regression analyses with the SEIO and Nino(0) indices are very consistent with the model experiments of Terray et al. (2007). Altogether these results show that during boreal spring, SST anomalies in the SEIO are able to trigger local feedbacks which become responsible for the persistence and northward propagation of the SST anomalies, as well as their significant impact on ISM variability during the following summer. In June, anomalies are temporarily weakened due to the negative feedback of convective clouds, which suggests a weak impact of the SEIO index during the early ISM season. However, ocean dynamics are also suggested to play an important role at this time, in particular near the west coast of Sumatra where the interaction between SST anomalies and upwelling processes allows SST and convection to be maintained in this region during the whole summer. By July, the warm anomalies resulting from the reduced upwelling are further amplified by the uptake of the positive WES feedback in the south Indian Ocean. This process increases the amount of available humidity over the south Indian Ocean and thus modulates the moisture transport to the Arabian Sea. Once the upwelling feedback is sufficiently developed and the SST-induced cyclonic anomaly over the eastern Indian Ocean has reached a sufficient amplitude, a dynamical response is triggered over the north Indian Ocean. The enhanced ISM circulation strengthens the moisture transport from the south Indian Ocean and the ensuing ISM rainfall over the Indian subcontinent in the late summer season. 
Moreover, the local processes described above are dynamically linked to different phases of ENSO in the Pacific Ocean. This last observation may have useful implications in terms of long-range seasonal prediction of the monsoon, as these local SST indices can offer relevant ISM forecasts as early as in late boreal winter (e.g SEIO and Nino(-1) indices) or early spring (e.g IOB index): the choice of the better forecasting index would then hinge on the concurrent phasing of the ENSO cycle in the Pacific ocean.

Nevertheless, we need to bear in mind that the 1979-2007 period has been shaped by two particularly strong and long-lasting El Niño events, e.g. the 1982-83 and 1997-98 warm events. It thus becomes relevant to ask ourselves at this point if, and to what extent, these extreme events have influenced our statistical results. In order to test the robustness of the previous results, a composite analysis is carried out during the summer of developing and decaying years of four 'normal' (1986-87, 1991-92, 1994-95 and 2002-2003) and two 'strong' (1982-83 and 1997-98) El Niño events (Figs. 13 and 14). The composite anomalous OLR patterns show that the El Niño events have a considerable impact on convective activity over the Indian subcontinent and its adjacent oceans during summer. However, this impact is entirely different depending on the phasing and the strength of the El Niño events which are being considered.

For instance, during the developing summer of the two strong El Niño events, the equatorial Pacific is marked by a particularly strong convective dipole whereas OLR anomalies are weak and poorly significant over India and the north Indian Ocean (Fig. 13b). Although the development of convection in the Pacific is less intense during the summer of 'normal' El Niño events (Fig. 13a), the positive OLR signal has gained significance over India and the Arabian Sea in the late summer (e.g. AS), suggesting that, at this time, local feedbacks in the Indian Ocean may be affecting the ISM rainfall variability, a finding consistent with the possible role of the SEIO index. It is also worth noticing that during these 'normal' El Niño events, anomalous convection is developed in the central equatorial Pacific rather than in the east during the late summer season. These significant negative OLR anomalies are associated with a horseshoe pattern and flanked by opposite anomalies on both sides along the equator, an OLR distribution which is reminiscent of the El Niño 'Modoki' events (Ashok et al., 2007; Weng et al., 2007; Kug et al., 2009). These works have distinguished the El Niño 'Modoki' phenomenon from the canonical El Niño in terms of SST characteristics, teleconnections and a more frequent occurrence during recent decades. In a recent work, Kug et al. (2009) classify 
the two types of El Niño events depending on their spatial pattern of SST anomalies, in the Niño4 region for the 'Modoki' event and Niño3 region for the conventional El Niño. However, our observational results are quite insensitive to the choice of ENSO indices, as correlation values with $\mathrm{Nino}(0)$ and Nino(-1) in Tables 2 and 3 are unchanged by the use of the Niño3 or Niño4 indices instead of Niño3.4. This highlights again the importance of local interactions within the Indian Ocean for the ISM rainfall.

Nevertheless, it seems important to point out that the two 'strong' episodes have a significant but reversed impact during their decaying phase (Fig. 14). Indeed, OLR patterns in Figure 14 are significant over the Indian region in the late summer of 1998 and 1983. In contrast, the OLR anomalies are weak and even of opposite sign during the decay of "normal" El Niño events. In other words, these composites suggest that the significant relationship which has been established between the Nino(-1) or IOB indices and ISM rainfall may be largely due to the occurrence of the two strongest El Niño events of the last century. This statistical bias thus sheds a doubt on the robustness and relevance of the IOB or Nino(-1) indices as ISM predictors. Moreover, it seems difficult to determine from this observational study which mechanisms are at play, and understand how the IOB index is able to affect ISM variability: whether it be directly via local processes in the Indian Ocean, or indirectly by accelerating the ENSO transition in the Pacific Ocean (Kug and Kang, 2006; Ohba and Ueda, 2007). Further work is needed in this direction, in particular to quantify the contribution of ENSO forcing on these interactions and reassess the merits of the IOB index as an intrinsic ISM predictor.

Likewise, our study and the recent work of Peings et al. (2009) have also highlighted the importance of variability in the Northwest Pacific Ocean for ISM prediction, as anomalies in this region are statistically significant during both the developing and decaying years of El Niño events. However, its contribution to ISM rainfall variability, regardless of ENSO, has also yet to be assessed. To this end, it would be interesting to use a fully coupled model and test its ability to simulate the Indian Ocean coupled interactions and their impact on ISM variability described in this paper. Numerical experiments may also be conducted as to unravel the relative contribution of each of these modes of variability and test their robustness as intrinsic ISM predictors, as already done for the SEIO index in Terray et al. (2007).

Finally, we would like to point out that our results regarding ISM interannual variability have shown an in-phase relationship between convective anomalies in the eastern equatorial Indian 
Ocean (just south of the equator) and over India. However, this OLR pattern seems to be in conflict with the OLR seesaw oscillation which has been observed on the intraseasonal timescales during boreal summer (Wang et al., 2005, 2006). Therefore, it will be of interest to analyze the links between these different timescales, with a particular focus on the interactions between the key SST indices from this study and subseasonal features associated with ISM variability.

Acknowledgments: Financial support from the Indo-French CEFIPRA project $\left(\mathrm{N}^{\circ}\right.$ 3907/1) is acknowledged. We thank Prince Xavier for providing us the ISM onset and withdrawal dates. We also thank the anonymous reviewers for their comments that improved this paper. The Hadley SST, NCAR/NCEP2 reanalysis and NOAA OLR datasets were provided by the NOAA/OAR/ESRL PSD, Boulder, Colorado, USA, from their Web site at URL: http://www.cdc.noaa.gov/. The OAFLUX products are obtained from the Woods Hole Oceanographic Institute through ftp://ftp.whoi.edu/pub/science/oaflux/data. Graphics have been prepared using the SAXO package of Sébastien Masson. 


\section{References}

Ailikun B, Yasunari T (2001) ENSO and Asian Summer Monsoon: Persistence and Transitivity in the Seasonal March. J Meteor Soc Jpn 79:145-159.

Alexander MA, Bladé I, Newman M, Lanzante JR, Lau N-C, Scott JD (2002) The atmospheric bridge: The influence of ENSO teleconnections on air-sea interaction over the global oceans. J Climate 15:2205-2231.

Alory G, Wijffels S, Meyers G (2007) Observed temperature trends in the Indian Ocean over 1960-1999 and associated mechanisms. Geophys Res Lett 34:L02606. doi: 10.1029/2006GL028044

Annamalai H, Liu P, Xie S-P (2005) Southwest Indian Ocean SST variability: Its local effect and remote influence on Asian monsoons. J Climate 18:4150-4167.

Ashok K, Guan Z, Yamagata T (2001) Influence of the Indian Ocean Dipole on the relationship between the Indian monsoon rainfall and ENSO. Geophys Res Lett 28:44994502.

Ashok K, Guan Z, Saji NH, Yamagata T (2004) Individual and combined influences of ENSO and the Indian Ocean Dipole on the Indian Summer Monsoon. J Climate 17:3141-3154.

Ashok K, Behera S, Rao AS, Weng HY, Yamagata T (2007) El Nino Modoki and its teleconnection. J Geophys Res 112:C11007. doi: 10.1029/2006JC003798

Behera SK, Krishnan R, Yamagata T (1999) Unusual ocean-atmosphere conditions in the tropical Indian Ocean during 1994. Geophys Res Lett 26:3001-3004.

Behera SK, Yamagata T (2001) Subtropical SST dipole events in the southern Indian Ocean. Geophys Res Lett 28:327-330.

Buermann W, Lintner BR, Bonfils C (2004) A wintertime Arctic Oscillation influence on 
early season Indian Ocean monsoon intensity. J Climate 18(13):2247-2269, doi:10.1175/JCLI3377.1, 2005.

Carton JA, Giese BS (2008) A reanalysis of ocean climate using Simple Ocean Data Assimilation (SODA). Mon Wea Rev 136:2999-3017.

Chiang JCH, Sobel AH (2002) Tropical Tropospheric Temperature Variations Caused by ENSO and Their Influence on the Remote Tropical Climate. J Climate 15: 2616-2631.

Chiodi AM, Harrison E (2007) Mechanisms of Summertime Subtropical Southern Indian Ocean Sea Surface Temperature Variability: On the Importance of Humidity Anomalies and the Meridional Advection of Water Vapor. J Climate 20:4835-4852.

Clark CO, Cole JE, Webster PJ (2000) Indian Ocean SST and Indian summer rainfall: Predictive relationships and their decadal variability. J Climate 13:2503-2519.

Cleveland RB, Cleveland WS, McRae JE, Terpenning I (1990) A Seasonal-Trend Decomposition Procedure Based on Loess (with Discussion). J Official Statistics 6:3-73.

Dominiak S, Terray P (2005) Improvement of ENSO prediction using a linear regression model with a Southern Indian Ocean Sea Surface Temperature Predictor. Geophys Res Lett 32:L18702. doi: 10.1029/2005GL023153

Du Y, Xie S-P, Huang G, Hu K-M (2009) Role of air-sea interaction in the long persistence of El Niño-induced North Indian Ocean warming. J Climate 22:2023-2038.

Ebisuzaki W (1997) A method to estimate the statistical significance of a correlation when the data are serially correlated. J Climate 10:2147-2153.

Findlater I (1969) A major low-level air current near the Indian Ocean during the northern summer. Q J Roy Meteor Soc 95:362-380. 
Fischer AS, Terray P, Delecluse P, Gualdi S, Guilyardi E (2005) Two Independent Triggers for the Indian Ocean Dipole/Zonal Mode in a Coupled GCM. J Climate 18:3428-3449.

Gadgil S, Vinayachandran PN, Francis PA, Gadgil S (2004) Extremes of the Indian summer monsoon rainfall, ENSO and Equatorial Indian Ocean Oscillation. Geophys Res Lett 31: L12213. doi: 10.1029/2004GL019733

Goswami BN, Xavier Prince K (2005) ENSO control on the South Asian Monsoon through the length of the rainy season. Geophys Res Lett 32:L18717. doi: 10.1029/2005GL023216

Harzallah A, Sadourny R (1997) Observed lead-lag relationships between Indian summer monsoon and some meteorological variables. Clim Dynam 13:635-648.

He H, Sui C-H, Jian M, Wen Z, Lan G (2003) The Evolution of Tropospheric Temperature Field and its Relationship with the Onset of Asian Summer Monsoon. J Meteor Soc Japan, 81(5):1201-1223.

Hermes JC, Reason CJC (2005) Ocean model diagnosis of interannual coevolving SST Variability in the South Indian and South Atlantic Oceans. J Climate 18:2864-2882.

Huang B, Kinter III JL (2002) Interannual variability in the tropical Indian Ocean. J Geophys Res 107:3199. doi: 10.1029/2001JC001278

Izumo T, De Boyer Montégut C, Luo J-J, Behera SK, Masson S, Yamagata T (2008) The Role of the Western Arabian Sea Upwelling in Indian Monsoon Rainfall Variability. J Climate 21:5603-5623.

Izumo T, Vialard J, Lengaigne M, De Boyer Montegut C, Behera SK, Luo J-J, Cravatte S, Masson S, Yamagata T (2010) Influence of the state of the Indian Ocean Dipole on the following year's El Niño. Nature Geoscience 3:168-172. doi: 10.1038/ngeo760 
Joseph PV, Pillai PV (1984) Air-sea interaction on a seasonal scale over north Indian Ocean. Part I: Interannual variations of sea surface temperature and Indian summer monsoon rainfall. Mausam 35:323-330.

Joseph PV, Eischeid JK, Pyle RJ (1994) Interannual variability of the onset of the Indian summer monsoon and its association with atmospheric features, El Nino, and sea surface temperature anomalies. J Climate 7:81-105.

Joseph PV, Sooraj KP, Rajan CK (2003) Conditions leading to monsoon over Kerala and associated Hadley cell. Mausam 54(1):155-164.

Joseph PV, Sijikumar S (2004) Intraseasonal variability of the low-level jet stream of the Asian summer monsoon. J Climate 17:1449-1458.

Kalnay et al. (1996) The NCEP/NCAR 40-year reanalysis project. Bull Am Meteor Soc 77:437-471.

Kanamitsu M, Ebisuzaki W, Woolen J, Potter J, Yang SK, Hnilo JJ, Fiorino M, Potter GL (2002) NCEP-DEO AMIP-II Reanalysis (R-2). Bull Am Meteor Soc 83:1631-1643.

Kawamura R, Matsuura T, lizuka S (2001) Role of equatorially asymmetric sea surface temperature anomalies in the Indian Ocean in the Asian summer monsoon and El Niño Southern Oscillation coupling. J Geophys Res 106:4681-4693.

Kinter JL, Miyakoda K, Yang S (2002) Recent change in the connection from the Asian Monsoon to ENSO. J Climate 15:1203-1215.

Klein SA, Soden BJ, Lau N-C (1999) Remote sea surface temperature variations during ENSO: evidence for a tropical atmospheric bridge. J Climate 12:917-932.

Krishnamurti TN (1971) Tropical east-west circulations during northern summer. J Atmos Sci 28:1342-1347.

Krishnan R, Mujumdar M, Vaidya V, Ramesh KV, Satyan V (2003) The abnormal summer 
monsoon of 2000. J Climate 16:1177-1194.

Krishnan R., Swapna P (2009) Significance influence of the boreal summer monsoon flow on the Indian Ocean response during dipole events. J Climate 22:5611-5634.

Kug J-S, Kang I-S (2006) Interactive feedback between ENSO and the Indian Ocean. J Climate 19:1784-1801.

Kug J-S, Jin F-F, An S-I (2009) Two types of El Nino Events: Cold Tongue El Nino and Warm Pool El Nino. J Climate 22:1499-1515.

Lau NC, Nath MJ (2000) Impact of ENSO on the variability of the Asian-Australian monsoons as simulated in GCM experiments. J Climate 13:4287-4309.

Lau NC, Nath MJ (2003) Atmosphere-Ocean Variations in the Indo-Pacific Sector during ENSO Episodes. J Climate 16:3-20.

Lau NC, Nath MJ (2004) Coupled GCM simulation of atmosphere-ocean variability associated with zonally asymmetric SST changes in the tropical Indian Ocean. J Climate $17: 245-265$.

Li T, Wang B, Chang CP, Zhang YS (2003) A theory for the Indian Ocean Dipole-Zonal Mode. J Atmos Sci 60:2119-2135.

Li T, Liu P, Fu X, Wang B, Meehl GA (2006) Tempo-spatial structures and mechanisms of the tropospheric biennial oscillation in the Indo-Pacific warm ocean regions. J Climate 19:3070-3087.

Li SL, Lu J, Huang G, Hu K (2008) Tropical Indian Ocean Basin Warming and East Asian Summer Monsoon: A Multiple AGCM Study. J Climate 21:6080-6088.

Liebmann B, Smith CA (1996) Description of a complete (interpolated) outgoing longwave radiation dataset. Bull Am Meteor Soc 77:1275-1277. 
Loschnigg J, Meehl GA, Webster PJ, Arblaster JM, Compo GP (2003) The Asian monsoon, the tropospheric biennial oscillation and the Indian Ocean dipole in the NCAR CSM. J Climate 16:2138-2158.

Meehl GA, Arblaster J (2002) The tropospheric biennial oscillation and the Asian-Australian monsoon rainfall. J Climate 15:722-744.

Meehl GA, Arblaster JM, Loschnigg J (2003) Coupled ocean-atmosphere dynamical processes in the tropical Indian and Pacific Oceans and the TBO. J Climate 16:2138-2158.

Nicholls N (1995) All-India summer monsoon rainfall and sea surface temperatures around northern Australia and Indonesia. J Climate 8:1463-1467.

Nitta T, Yamada S (1989) Recent warming of tropical sea surface temperature and its relationship to the Northern Hemisphere circulation. J Meteor Soc Jpn 67:375-383.

Ohba M, Ueda H (2007) An impact of SST anomalies in the Indian Ocean in acceleration of the El Niño to La Niña transition. J Meteor Soc Jpn 85:335-348.

Pant GB, Rupa Kumar K (1997) Climates of South Asia. John Wiley \& Sons, Chichester, (ISBN 0-471-94948-5), 320 pp.

Park H-S, Chiang JCH, Lintner BR, Zhang JG (2010) The delayed effect of major El Nino events on Indian monsoon rainfall. J Climate 23:932-946.

Parthasarathy B, Munot AA, Kothawale DR (1995) All India monthly and seasonal rainfall series: 1871-1993. Theor Appl Climatol 49:217-224.

Peings Y, Douville H, Terray P (2009) Extended winter Pacific North America oscillation as a precursor of the Indian summer monsoon rainfall. Geophys Res Lett 36:L11710. doi: 10.1029/2009GL038453

Ramesh Kumar MR, Sankar S, Reason C (2008) An investigation into the conditions leading to monsoon onset over Kerala. Theor Appl Climatol. doi: 10.1007/s00704-008-0376-y 
Rao KG, Goswami BN (1988) Interannual variations of sea surface temperature over the Arabian Sea and the Indian monsoon: A new perspective. Mon Wea Rev 116:558-568.

Rayner NA, Parker DE, Horton EB, Folland CK, Alexander LV, Rowell DP, Kent EC, Kaplan A (2003) Global analyses of sea surface temperature, sea ice, and night marine air temperature since the late nineteenth century. J Geophys Res 108(D14)4407. doi: 10.1029/2002JD002670

Reason CJC, Allan RJ, Lindesay JA, Ansell TJ (2000) ENSO and climatic signals across the Indian Ocean basin in the global context: Part I. Interannual composite patterns. Int J Climatol 20:1285-1327.

Reason CJC, Rouault M, Melice J-L, Jagadeesha D (2002) Winter rainfall variability in SW South Africa and large scale ocean-atmosphere interactions. Met Atmos Phys (Special Issue on Atmosphere-surface interactions) 80(1-4):19-29.

Rupa Kumar K, Krishnakumar K, Ashrit RG, Patwardhan SK, Pant GB (2002) in Climate Change and India, P. R. Shukla et al., Eds. Tata McGraw Hill, New Delhi, pp. 24-75.

Saji NH, Goswami BN, Vinayachandran PN, Yamagata TA (1999) Dipole Mode in the Tropical Indian Ocean. Nature 401:360-363.

Schott FA, Xie SP, McCreary Jr. JP (2009) Indian Ocean circulation and climate variability. Rev Geophys 47. doi: 10.1029/2007RG000245

Shukla J, Misra BM (1977) Relationships between sea surface temperature and wind speed over the central Arabian Sea and monsoon rainfall over India. Mon Wea Rev 105:798-1002.

Shukla J (1987) Interannual variability of monsoons. Monsoons. J.S. Fein and P.L. Stephens, Eds., Wiley, 399-464.

Soman MK, Krishnakumar K (1993) Space time evolution of meteorological features associated with the onset Indian Summer monsoon. Mon Rev 121:1177-1194. 
Swapna P, Krishnan R (2008) Equatorial undercurrents associated with Indian Ocean Dipole events during contrasting summer monsoons. Geophys Res Lett 35:L14S04. doi: 10.1029/2008GL033430

Terray P (1994) An evaluation of climatological data in the Indian Ocean area. J Meteor Soc Jpn 72:359-386.

Terray P (1995) Space/Time structure of monsoons interannual variability. J Climate 8:25952619.

Terray P, Delecluse P, Labattu S, Terray L (2003) Sea Surface Temperature Associations with the Late Indian Summer Monsoon. Clim Dynam 21:593-618.

Terray P, Dominiak S (2005) Indian Ocean Sea Surface Temperature and El Niñ o-Southern Oscillation: a new perspective. J Climate 18:1351-1368.

Terray P, Dominiak S, Delecluse P (2005) Role of the southern Indian Ocean in the transitions of the monsoon-ENSO system during recent decades. Clim Dynam 24:169-195. doi: 10.1007/s00382-004-0480-3

Terray P, Chauvin F, Douville H (2007) Impact of southeast Indian Ocean Sea Surface Temperature anomalies on monsoon-ENSO-dipole variability in a coupled ocean-atmosphere model. Clim Dynam 28:553-580. doi:10.1007/s00382-006-0192-y

Terray P (2010) Southern Hemisphere extro-tropical forcing: A new paradigm for El NiñoSouthern Oscillation. Submitted to Clim Dynam.

Wang B, Wu R, Lau K-M (2001) Interannual variability of the Asian summer monsoon: contrasts between the Indian and the Western North Pacific-East Asian monsoons. J Climate 14:4073-4090.

Wang B, Wu R, Li T (2003) Atmosphere-warm ocean interaction and its impacts on AsianAustralian monsoon variation. J Climate 16:1195-1211. 
Wang B, Webster PJ, Teng H (2005) Antecedents and Selfinduction of active-break south Asian monsoon unraveled by satellites. Geophys Res Lett 32:L04704. doi: 10.1029/2004GL020996

Wang B, Webster PJ, Kikuchi K, Yasunari T, Qi Y (2006) Boreal summer quasi-monthly oscillation in the global tropics. Clim Dynam 27:661- 675.

Weare B (1979) A statistical study of the relationships between ocean surface temperatures and the Indian monsoon. J Atmos Sci 36:2279-2291.

Webster PJ, Magana VO, Palmer TN, Shukla J, Tomas RA, Yanai M, Yasunari T (1998) Monsoons: Processes, predictability and the prospects for prediction. J Geophys Res 103(C7):14 451-14 510.

Webster PJ, Moore AM, Loschnigg JP, Leben RR (1999) Coupled ocean-atmosphere dyniamics in the Indian Ocean during 1997-1998. Nature 401:356-360.

Webster PJ, Hoyos C (2010) Beyond the spring barrier? Nature Geoscience 3:152-153. doi: $10.1038 /$ ngeo 760

Weng H, Ashok K, Behera SK, Rao SA and Yamagata T (2007) Impacts of El Nino Modoki on dry/wet conditions in the Pacific rim during boreal summer. Clim Dynam 29:113-125. doi: $10.1007 / \mathrm{s} 00382-007-0234-0$

Wu R, Kirtman BP, Krishnamurthy V (2008) An asymmetric mode of tropical Indian Ocean rainfall variability in boreal spring. J Geophys Res 113:D05104. doi: 10.1029/2007JD009316

Xavier PK, Marzin C, Goswami BN (2007) An objective definition of the Indian summer monsoon season and a new perspective on ENSO-monsoon relationship. Q J Meteorol Soc 133:749-764.

Xie S-P, Annamalai H, Schott FA, McCreary JP (2002) Structure and mechanisms of south Indian Ocean climate variability. J Climate 15:864-878. 
Xie S-P, Hu K, Hafner J, Du Y, Huang G, Tokinaga H (2009) Indian Ocean capacitor effect on Indo-western Pacific climate during the summer following El Niño. J Climate 22:730-747.

Yang J, Liu Q, Xie S-P, Liu Z, Wu L (2007) Impact of the Indian Ocean SST basin mode on the Asian summer monsoon. Geophys Res Lett 34:L02708. doi: 10.1029/2006GL028571

Yamagata T, Behera SK, Luo J-J, Masson S, Jury M, Rao S (2004) Coupled oceanatmosphere variability in the tropical Indian Ocean. In: Earth Climate: The OceanAtmosphere Interaction. Geophys Monogr Ser 147, edited by Wang C, Xie S-P, Carton JA, pp. 189-212, AGU, Washington, D. C.

Yu L, Jin X, Weller RA (2008) Multidecade Global Flux Datasets from the Objectively Analyzed Air-sea Fluxes (OAFlux) Project: Latent and sensible heat fluxes, ocean evaporation, and related surface meteorological variables. Woods Hole Oceanographic Institution, OAFlux Project Technical Report. OA-2008-01, 64pp. Woods Hole. Massachusetts. 


\section{Figure captions:}

Figure 1: Lead-lag correlations between bimonthly SST indices and the ISM rainfall in (a) June-July and (b) August-September for the 1979-2007 period.

The correlation with the Nino index is plotted in green, the IOB in blue, the SEIO in red and the IOD in black. Correlation values exceeding the $10 \%$ probability level according to the phase-scrambling bootstrap test of Ebisuzaki (1997) with 999 samples are marked by a diamond.

Figure 2: Bimonthly SST anomalies regressed onto the Nino(-1) index (panels a to d) and IOB index (panels e to h) from February-March (FM) to August-September (AS). Regressions that are above the $90 \%$ confidence level estimated with a phase-scrambling bootstrap test with 999 sampled are encircled. The standard deviation of the Niño3.4 (IOB) index is given at the bottom of the left (right) panels.

Figure 3: Regression of Nino(-1) index onto (a) bimonthly heat content anomalies averaged over the first $130 \mathrm{~m}$ layer of the ocean, (b) wind anomalies at $10 \mathrm{~m}$, (c) geopotential (shading) and 200hPa wind anomalies (arrows), and (d) tropospheric mean temperatures (averaged from 850 to $200 \mathrm{hPa}$ ), all in April-May (AM). Regressions that are above the $90 \%$ confidence level estimated with a phase-scrambling bootstrap test with 999 sampled are encircled. Only wind anomalies that are above the $90 \%$ confidence level are shown. The standard deviation of the Niño3.4 index is given at the bottom of the panels.

Figure 4: Regression of Nino(-1) index onto monthly OLR anomalies from May to September. Regressions that are above the 90\% confidence level estimated with a phasescrambling bootstrap test with 999 sampled are encircled. The standard deviation of the Niño3.4 index is given at the bottom of the panels.

Figure 5: Regression of Nino(-1) index onto monthly SLP (shading) and $850 \mathrm{hPa}$ wind anomalies (arrows) from May to September. Regressions that are above the $90 \%$ confidence level estimated with a phase-scrambling bootstrap test with 999 sampled are encircled. Only wind anomalies that are above the $90 \%$ confidence level are shown. The standard deviation of the Niño3.4 index is given at the bottom of the panels. 
Figure 6: Regression of Nino(-1) index onto monthly wind speed (panels a to c) and upward latent heat flux anomalies (panels d to f) from June to August. Regressions that are above the $90 \%$ confidence level estimated with a phase-scrambling bootstrap test with 999 sampled are encircled. The standard deviation of the Niño3.4 index is given at the bottom of the left panels.

Figure 7: Regression of Nino(-1) index onto monthly air temperature at $2 \mathrm{~m}$ (shading) and $850 \mathrm{hPa}$ wind anomalies (arrows) in June and July. Regressions that are above the 90\% confidence level estimated with a phase-scrambling bootstrap test with 999 sampled are encircled. Only wind anomalies that are above the $90 \%$ confidence level are shown. The standard deviation of the Niño3.4 index is given at the bottom of the panels.

Figure 8: Regression of a Northwest Pacific summer monsoon dynamical index onto bimonthly OLR anomalies in July-August. The Northwest Pacific monsoon index is defined as the meridional difference of $850 \mathrm{hPa}$ zonal wind anomalies between a northern $\left(20^{\circ}-30^{\circ} \mathrm{N}\right.$, $\left.110^{\circ}-140^{\circ} \mathrm{E}\right)$ and a southern region $\left(5^{\circ}-15^{\circ} \mathrm{N}, 100^{\circ}-130^{\circ} \mathrm{E}\right)$ averaged over June-July-August, following Wang et al. (2001). The standard deviation of this index is given at the bottom of the panel. Regressions that are above the $90 \%$ confidence level estimated with a phasescrambling bootstrap test with 999 sampled are encircled.

Figure 9: Bimonthly SST anomalies regressed onto the Nino(0) index (panels a to d) and SEIO index (panels e to h) from February-March (FM) to August-September (AS). Regressions that are above the $90 \%$ confidence level estimated with a phase-scrambling bootstrap test with 999 sampled are encircled. The standard deviation of the Niño3.4 (SEIO) index is given at the bottom of the left (right) panels.

Figure 10: Regression of SEIO index onto bimonthly (a) OLR anomalies, (b) SLP (shading) and $850 \mathrm{hPa}$ wind anomalies (arrows), (c) upward latent heat flux anomalies and (d) wind speed anomalies, all in April-May (AM). Regressions that are above the $90 \%$ confidence level estimated with a phase-scrambling bootstrap test with 999 sampled are encircled. Only wind anomalies that are above the $90 \%$ confidence level are shown. The standard deviation of the SEIO index is given at the bottom of the panels. 
Figure 11: Regression of SEIO index onto monthly OLR anomalies from June to September (panels a to d). Regressions that are above the $90 \%$ confidence level estimated with a phasescrambling bootstrap test with 999 sampled are encircled. The standard deviation of the SEIO index is given at the bottom of the panels.

Figure 12: Regression of SEIO index onto monthly wind speed (panels a to d) and upward latent heat flux anomalies (panels e to $\mathrm{h}$ ) from June to September. Regressions that are above the $90 \%$ confidence level estimated with a phase-scrambling bootstrap test with 999 sampled are encircled. The standard deviation of the SEIO index is given at the bottom of the left panels.

Figure 13: OLR composites during the development of (a) "normal" El Nino events (198687, 1991-92, 1994-95 and 2002-2003) and (b) "strong" El Nino events (1982-83 and 199798), in June-July (left panels) and August-September (right panels). Composite anomalies that are above the $90 \%$ confidence level using the Monte-Carlo procedure of Terray et al. (2003) are encircled.

Figure 14: OLR composites during the decaying phase of (a) "normal" El Nino events (in 1986, 1992, 1995 and 2003) and (b) “strong” El Nino events (in 1983 and 1998), in June-July (left panels) and August-September (right panels). Composite anomalies that are above the 90\% confidence level using the Monte-Carlo procedure of Terray et al. (2003) are encircled. 


\section{Table captions:}

Table 1: Description of the different indices used in this study and their standard deviation, based of HadISST1.1 SST data over the 1979-2007 period.

Table 2: Cross-correlations between the key SST indices (defined in Table 1) and the ISM rainfall (ISMR) in seasonal and monthly mean from June to September, for the 1979-2007 period.

The coefficients exceeding the 10\%, 5\% and 5\% confidence levels according to the phasescrambling bootstrap test of Ebisuzaki (1997) with 999 samples are followed by one star (*), two stars $(* *)$ and three stars $(* * *)$, respectively.

Table 3: Cross-correlations between the key SST indices (defined in Table 1) and the onset and withdrawal dates of the ISM, for the 1979-2005 period.

The onset and withdrawal dates are estimated from NCEP/NCAR reanalysis, using the objective definitions of Xavier et al. (2007). Note that the IMD onset dates (based on rainfall over Kerala) available during the 1979-2001 period are also used for comparison purpose. The coefficients exceeding the $10 \%, 5 \%$ and 5\% confidence levels according to the phasescrambling bootstrap test of Ebisuzaki (1997) with 999 samples are followed by one star (*), two stars $(* *)$ and three stars $(* * *)$, respectively. 
TABLE 1

\begin{tabular}{|c|c|c|c|c|}
\hline & ENSO & IOD & IOSD & IOB \\
\hline $\begin{array}{l}\text { Index name } \\
\text { (reference) }\end{array}$ & $\begin{array}{l}\text { NINO index } \\
\text { (Nino3.4 index) }\end{array}$ & $\begin{array}{c}\text { IOD index } \\
\text { (Saji et al., 1999) }\end{array}$ & $\begin{array}{c}\text { SEIO index } \\
(\text { Terray and } \\
\text { Dominiak, 2005) }\end{array}$ & $\begin{array}{c}\text { IOB index } \\
\text { (Yang et al., 2007) }\end{array}$ \\
\hline $\begin{array}{c}\text { Geographical } \\
\text { domain }\end{array}$ & $\begin{array}{l}\text { Eastern tropical } \\
\text { Pacific Ocean : } \\
\quad\left(5^{\circ} \mathrm{N}-5^{\circ} \mathrm{S} ;\right. \\
\left.170^{\circ} \mathrm{W}-120^{\circ} \mathrm{W}\right)\end{array}$ & $\begin{array}{c}\text { Equatorial Indian } \\
\text { Ocean: } \\
\text { West box }\left(50^{\circ} \mathrm{E}-\right. \\
\left.70^{\circ} \mathrm{E} ; 10^{\circ} \mathrm{N}-10^{\circ} \mathrm{S}\right) \\
\text { minus } \\
\text { East box }\left(90^{\circ} \mathrm{E}-\right. \\
\left.110^{\circ} \mathrm{E} ; 10^{\circ} \mathrm{S}-0^{\circ} \mathrm{S}\right)\end{array}$ & $\begin{array}{l}\text { South East Indian } \\
\text { Ocean: } \\
\left(90^{\circ}-122^{\circ} \mathrm{E} ; 5^{\circ}-\right. \\
\left.45^{\circ} \mathrm{S}\right)\end{array}$ & $\begin{array}{c}\text { Tropical Indian } \\
\text { Ocean: } \\
\left(40^{\circ}-110^{\circ} \mathrm{E} ; 20^{\circ} \mathrm{S}-\right. \\
\left.20^{\circ} \mathrm{N}\right)\end{array}$ \\
\hline $\begin{array}{l}\text { Temporal } \\
\text { definition }\end{array}$ & $\begin{array}{l}\text { December- } \\
\text { January }\end{array}$ & $\begin{array}{l}\text { September- } \\
\text { October- } \\
\text { November }\end{array}$ & February-March & April-May \\
\hline $\begin{array}{c}\text { Standard } \\
\text { Deviation }\left({ }^{\circ} \mathrm{C}\right)\end{array}$ & 1.10 & 0.40 & 0.31 & 0.21 \\
\hline
\end{tabular}


TABLE 2

\begin{tabular}{c|c|c|c|c|c} 
& $\begin{array}{c}\text { ISMR } \\
\text { (JJAS) }\end{array}$ & $\begin{array}{c}\text { ISMR } \\
(\text { June) }\end{array}$ & $\begin{array}{c}\text { ISMR } \\
(\text { July) }\end{array}$ & $\begin{array}{c}\text { ISMR } \\
\text { (August) }\end{array}$ & $\begin{array}{c}\text { ISMR } \\
\text { (September) }\end{array}$ \\
\hline IOB & 0.19 & $\mathbf{- 0 . 3 2}^{* *}$ & 0.03 & 0.23 & $\mathbf{0 . 4 4}^{* * *}$ \\
\hline Nino(-1) & 0.18 & $\mathbf{- 0 . 4 6}^{* * *}$ & 0.05 & $0.32^{*}$ & $\mathbf{0 . 4 5}$ \\
\hline SEIO & $0.39^{* * *}$ & -0.19 & 0.21 & 0.27 & $\mathbf{0 . 5 6}$ \\
\hline Nino(0) & $-0.40^{* * * *}$ & 0.06 & $-0.44^{* * *}$ & 0.11 & $\mathbf{- 0 . 5 2}^{* * *}$ \\
\hline IOD(0) & -0.16 & -0.01 & -0.21 & 0.15 & -0.24 \\
\hline IOD(-1) & 0.24 & -0.30 & 0.19 & 0.25 & $0.34^{* *}$
\end{tabular}

${ }^{*}: P<0.1 ;{ }^{* * *}: P<0.05 ;{ }^{* * *}: P<0.005$ 
TABLE 3

\begin{tabular}{c|c|c|c}
\multirow{2}{*}{} & \multicolumn{2}{|c|}{ Onset dates } & \multirow{2}{*}{$\begin{array}{c}\text { Withdrawal } \\
\text { dates }\end{array}$} \\
\cline { 2 - 3 } & NCEP & IMD & $\mathbf{0 . 3 6}^{*}$ \\
\hline IOB & $\mathbf{0 . 4 7}$ & 0.22 & $\mathbf{0 . 3 4}^{* * *}$ \\
\hline Nino(-1) & $\mathbf{0 . 6 3}$ & 0.34 & $\mathbf{0 . 6 3}^{* * * * *}$ \\
\hline SEIO & 0.08 & 0.13 & $\mathbf{- 0 . 5 5}^{* * * *}$ \\
\hline Nino(0) & 0.22 & 0.22 & $\mathbf{- 0 . 4 4}^{* * *}$ \\
\hline IOD(0) & 0.18 & 0.08 & $0.43^{* *}$
\end{tabular}

${ }^{*}: P<0.1 ;{ }^{* *}: P<0.05 ;{ }^{* * *}: P<0.005$ 
(a)

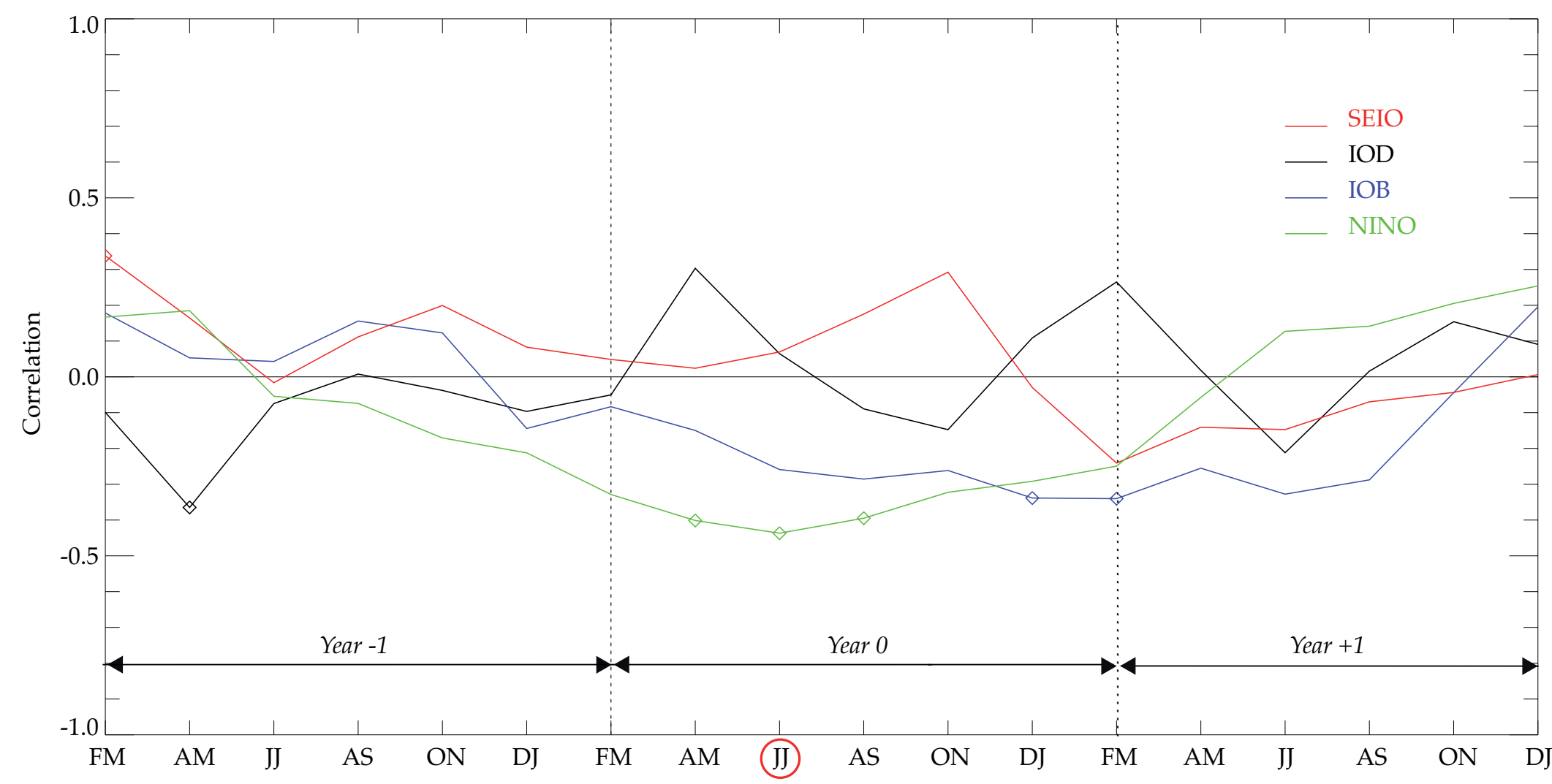

(b)

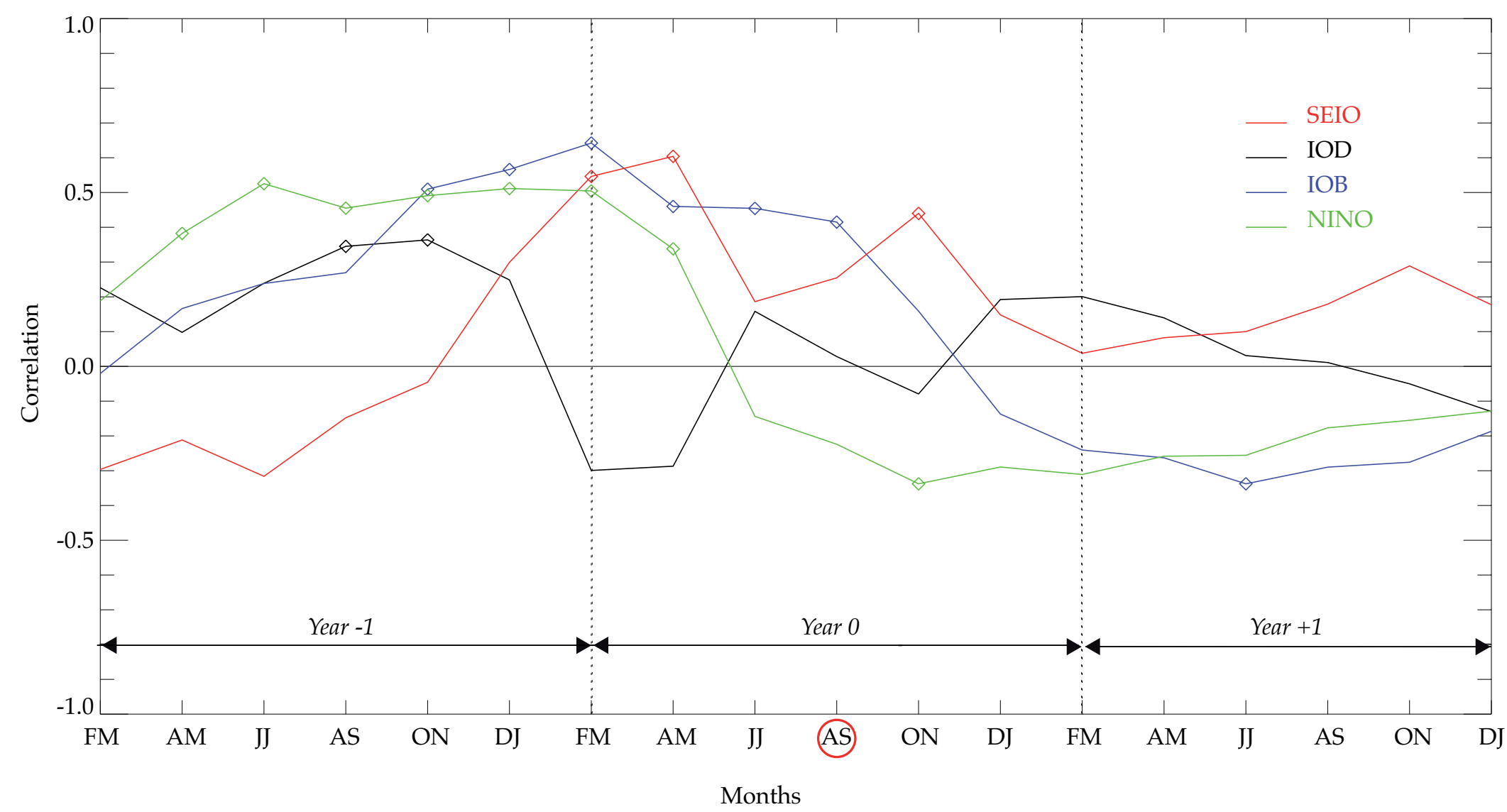


(a)

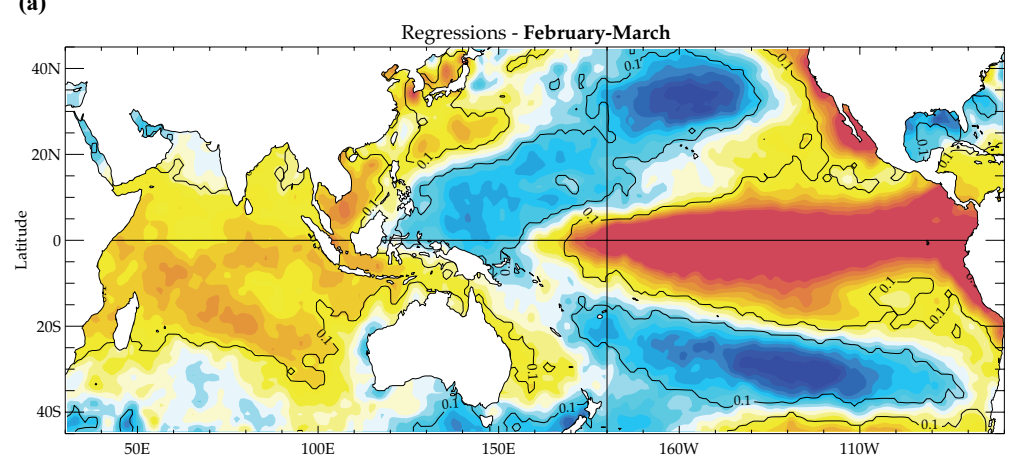

(b)

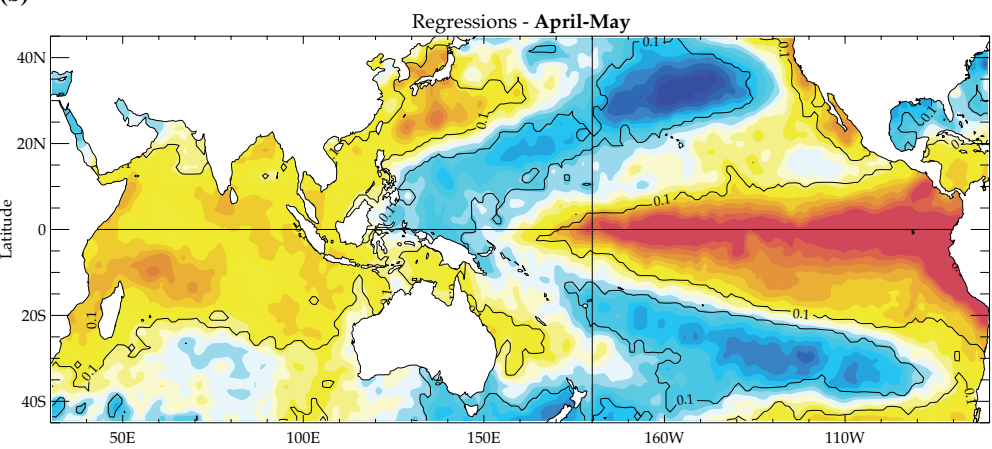

(c)

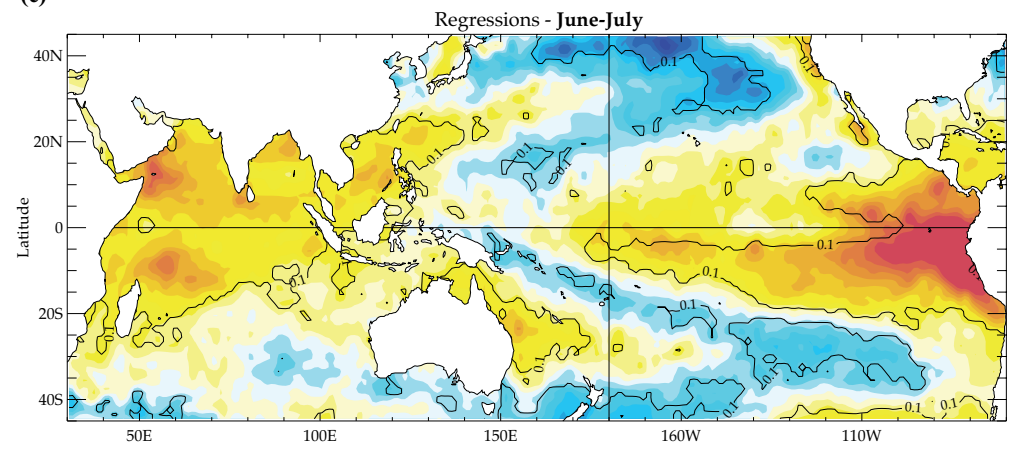

(d)

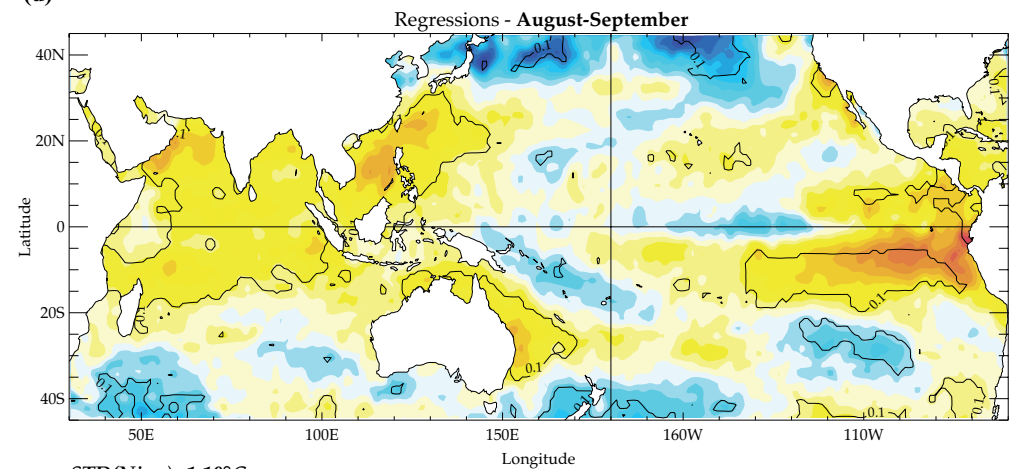

(e)

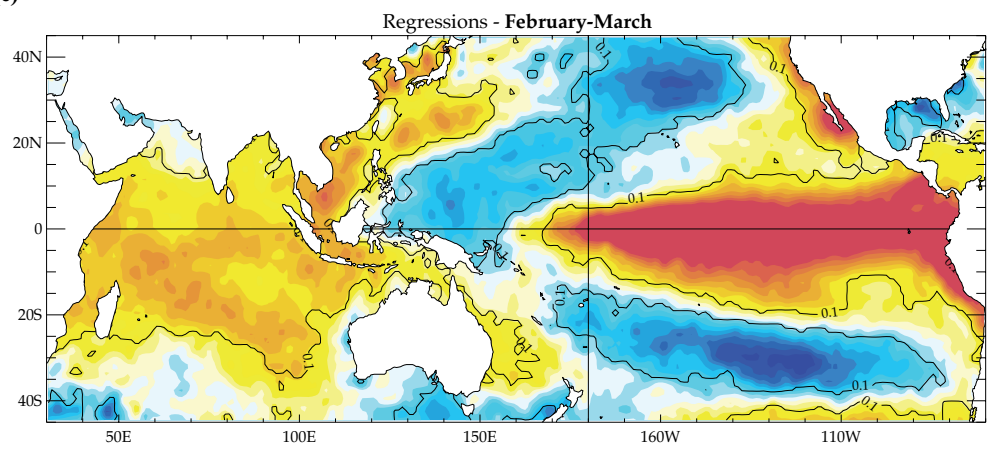

(f)

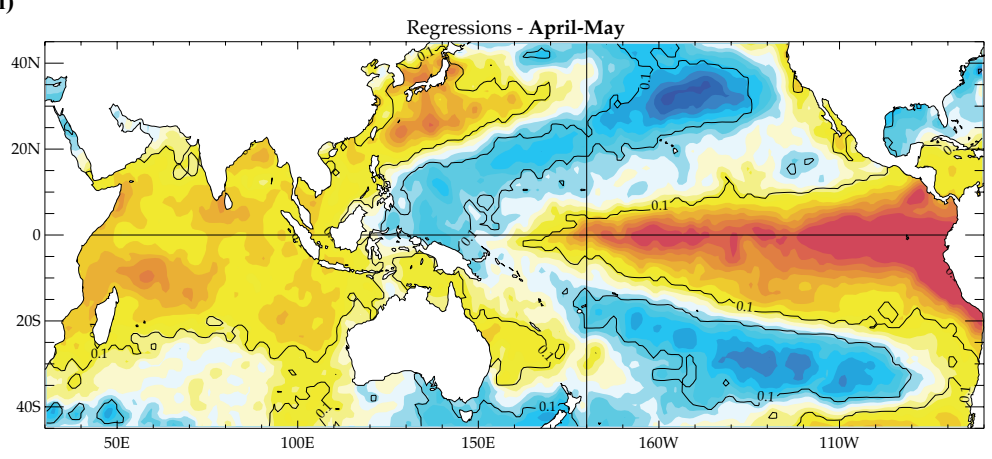

(g)

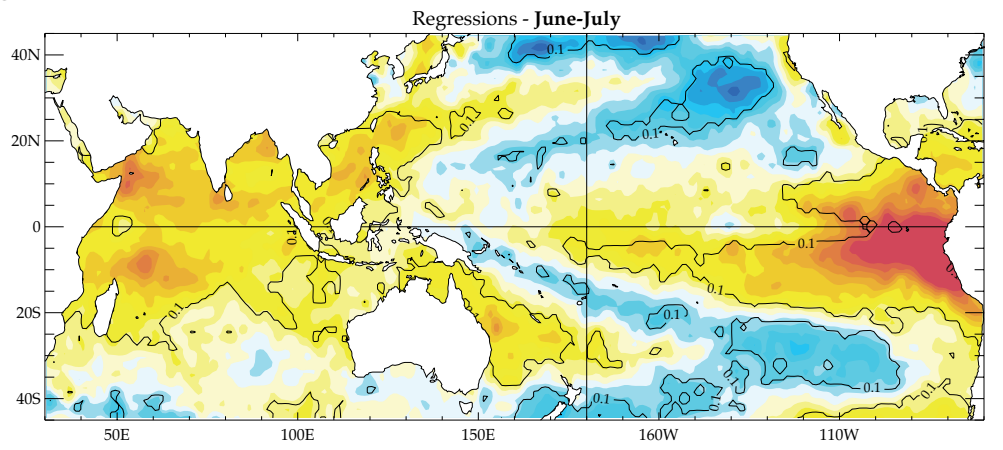

(h)

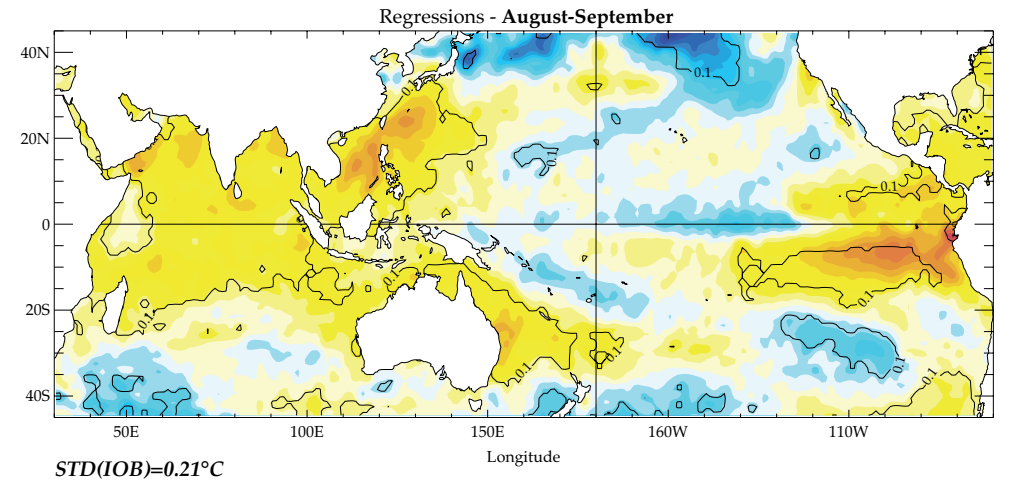


(a)
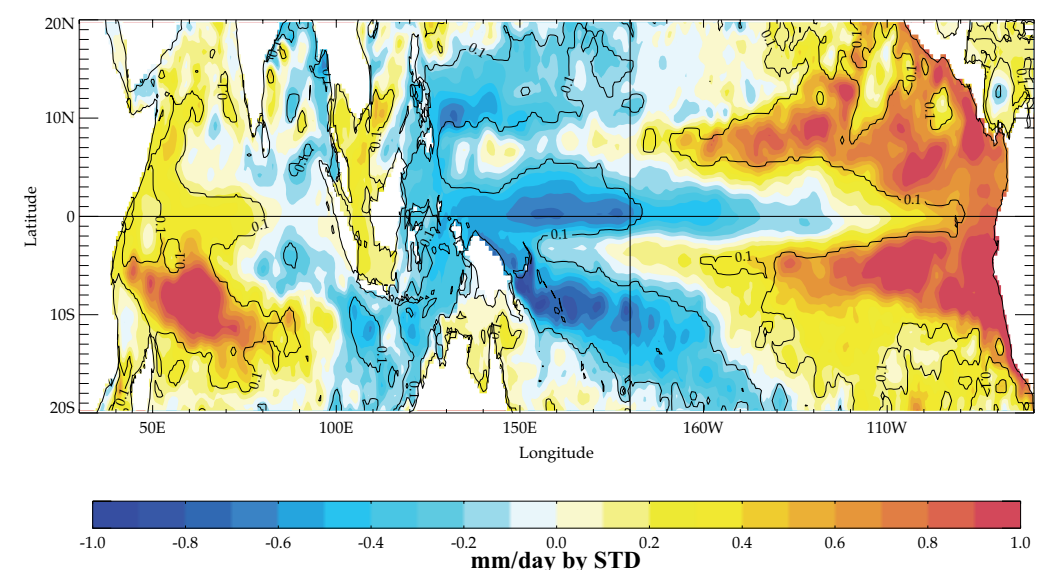

(b)

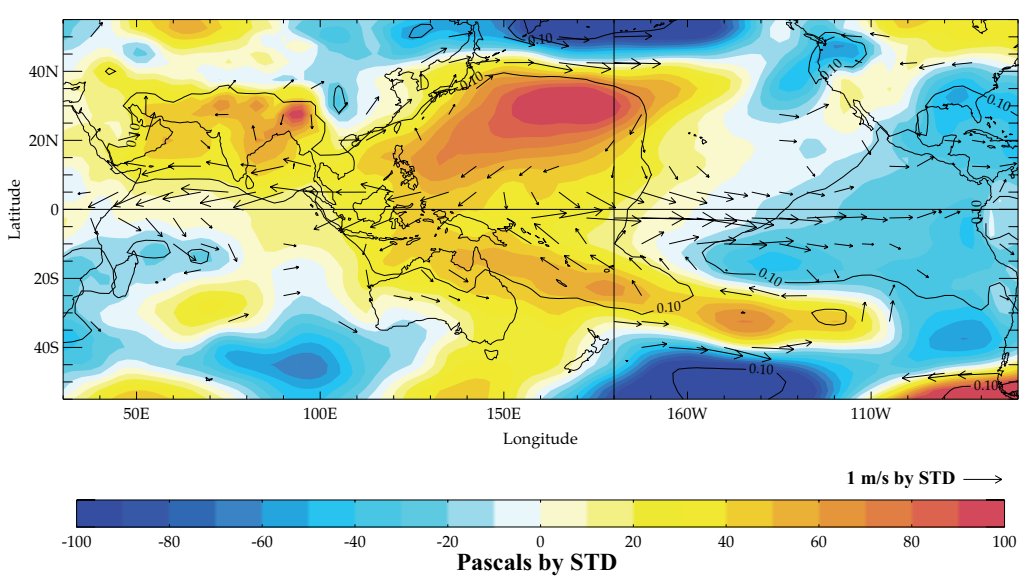

(c)
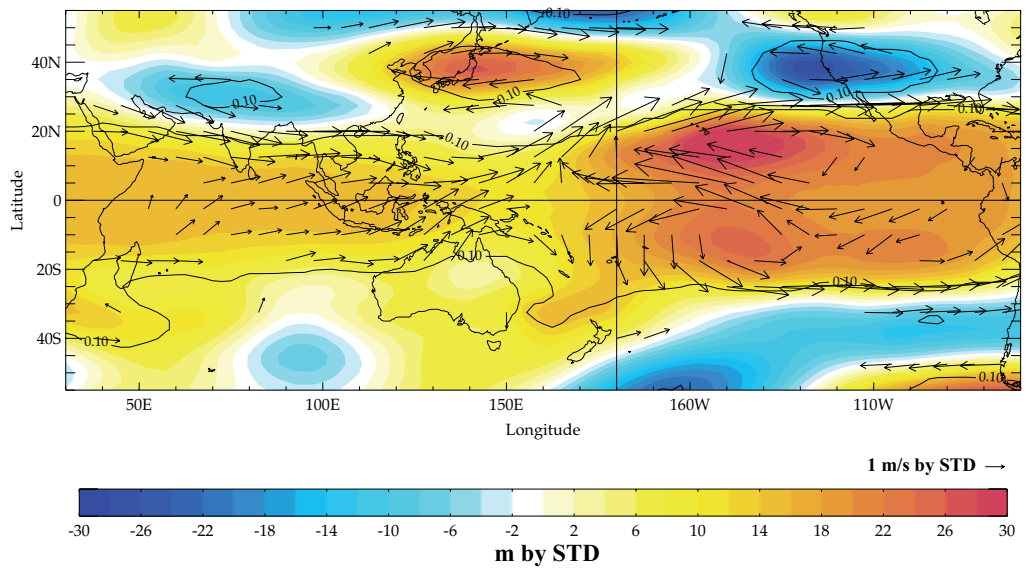

(d)

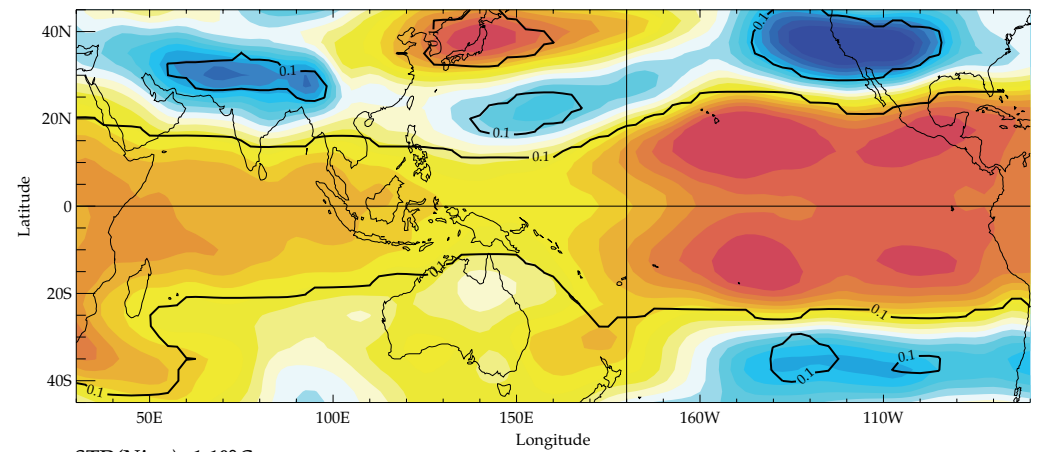

$S T D($ Nino $)=1.10^{\circ} \mathrm{C}$

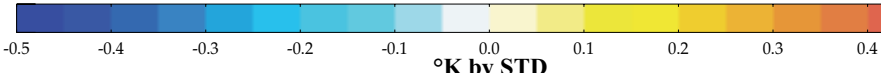


(a)

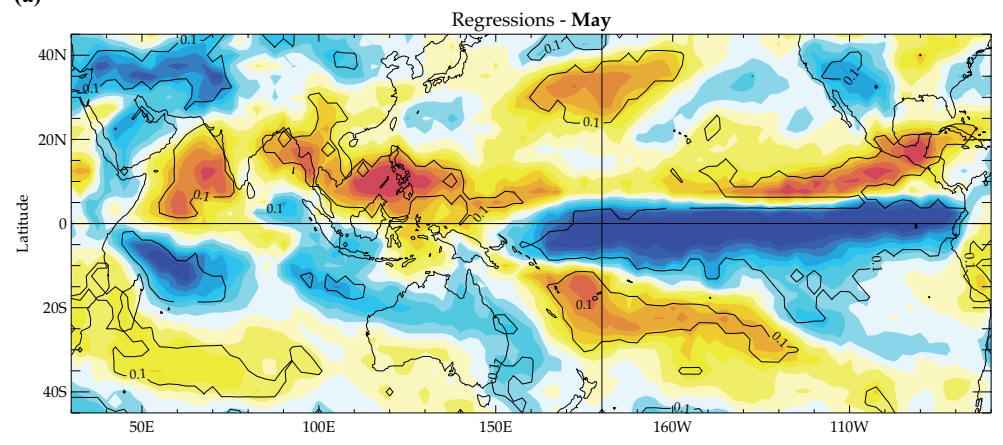

(b)

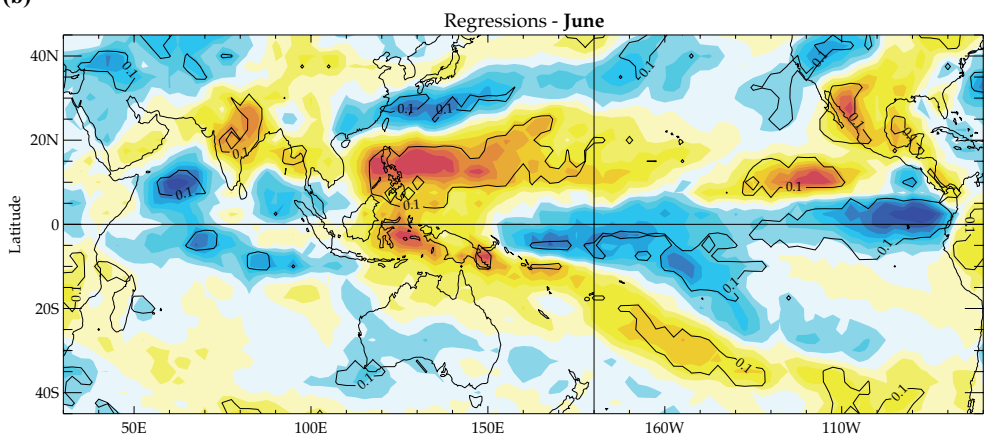

(c)

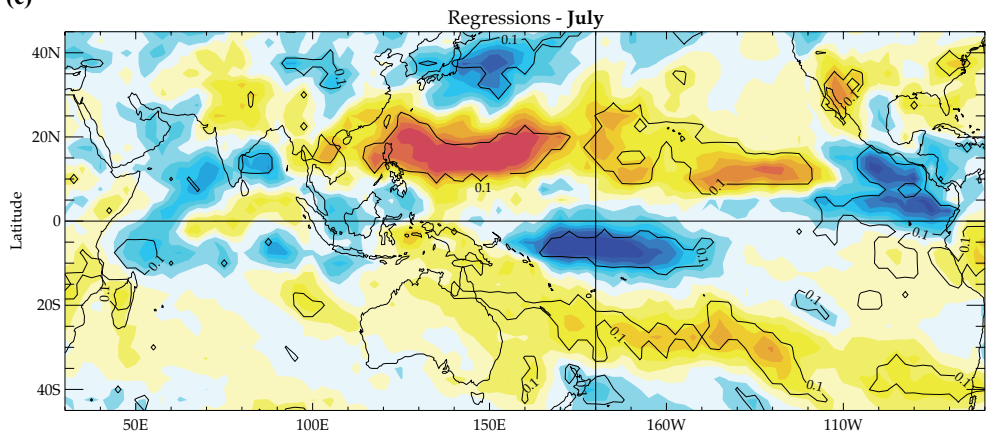

(d)

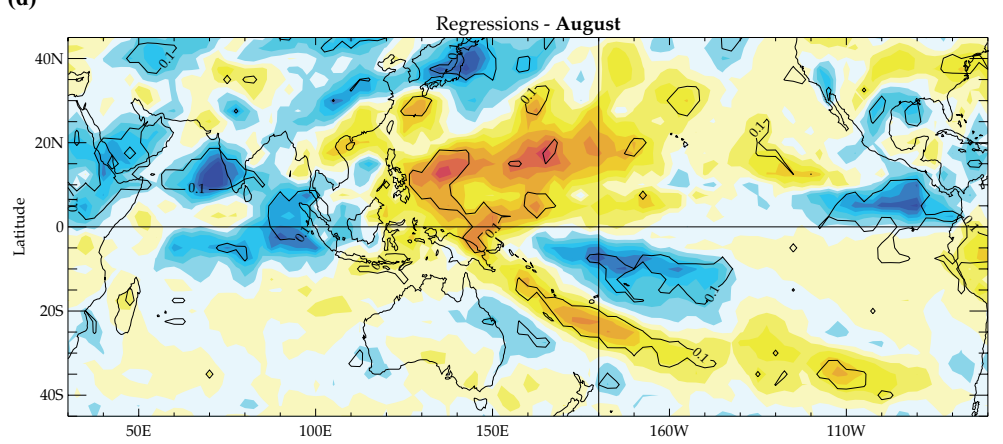

(e)

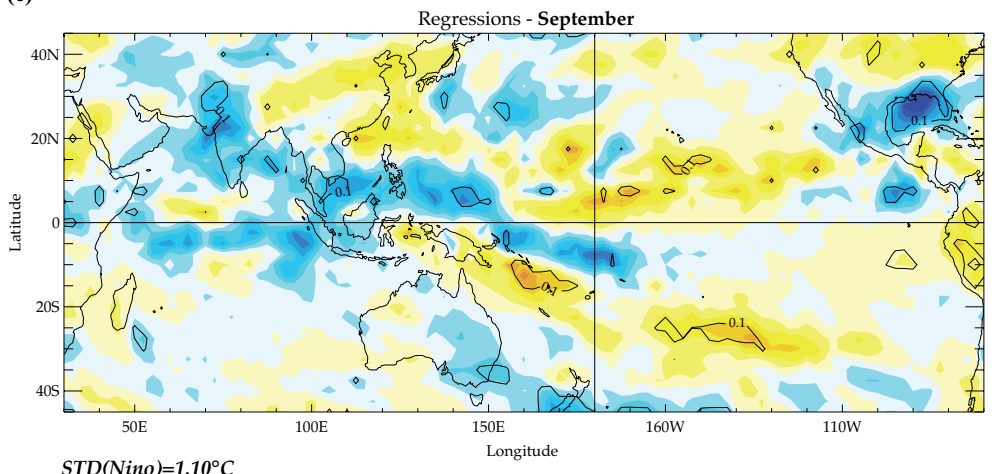

$S T D($ Nino $)=1.10^{\circ} \mathrm{C}$

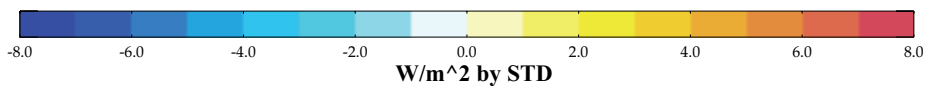


Figure5

(a)

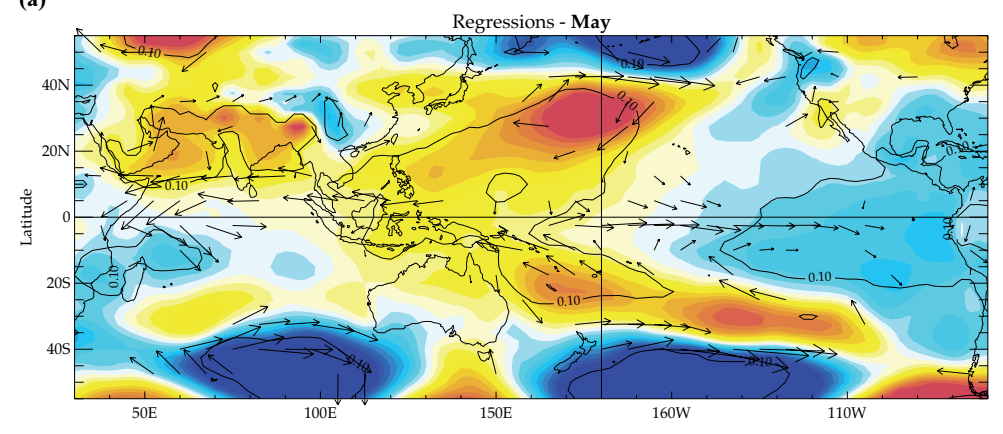

(b)

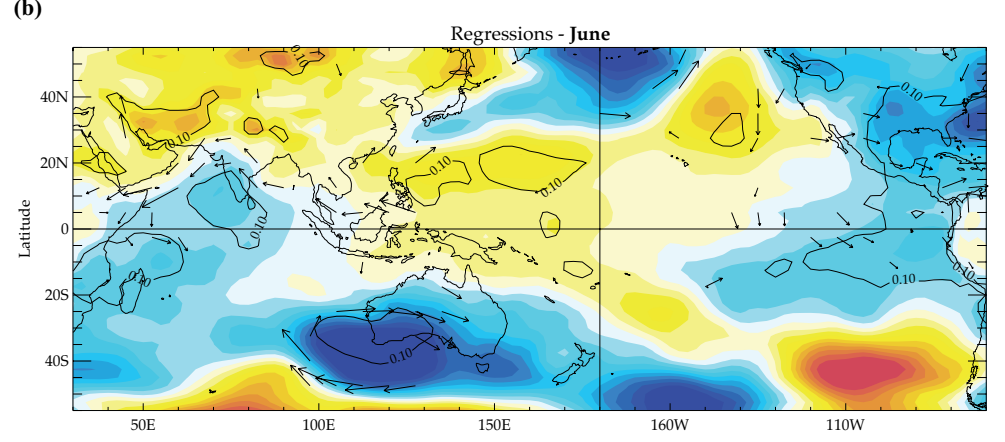

(c)

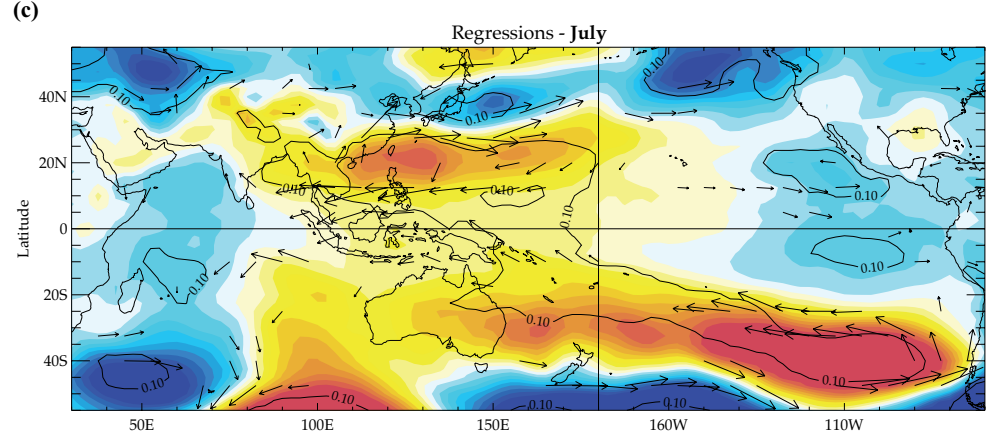

(d)

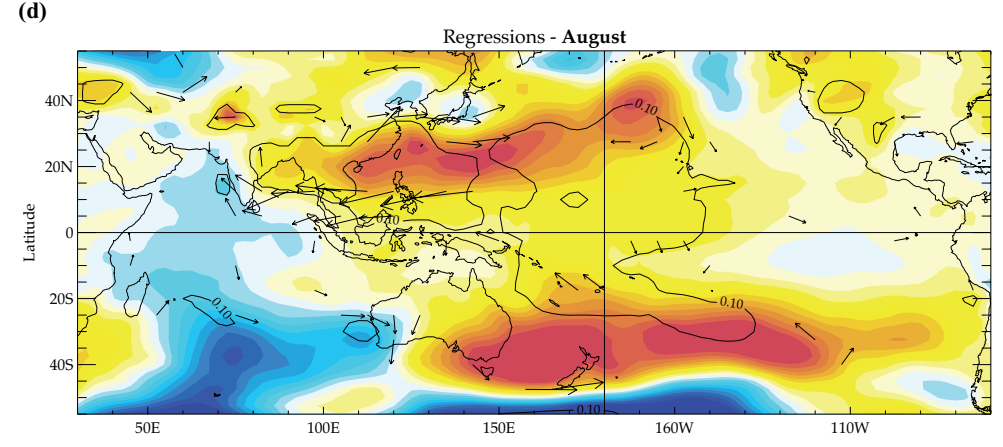

(e)

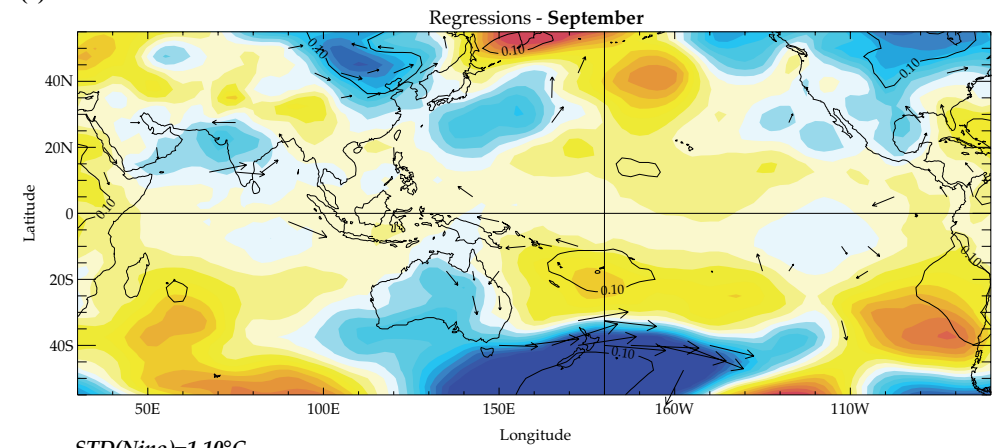

$S T D(N i n o)=1.10^{\circ} \mathrm{C}$

$1 \mathrm{~m} / \mathrm{s}$ by STD $\longrightarrow$

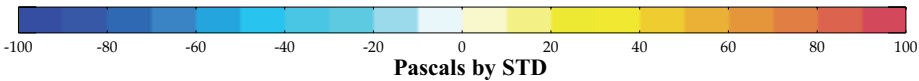


(a)

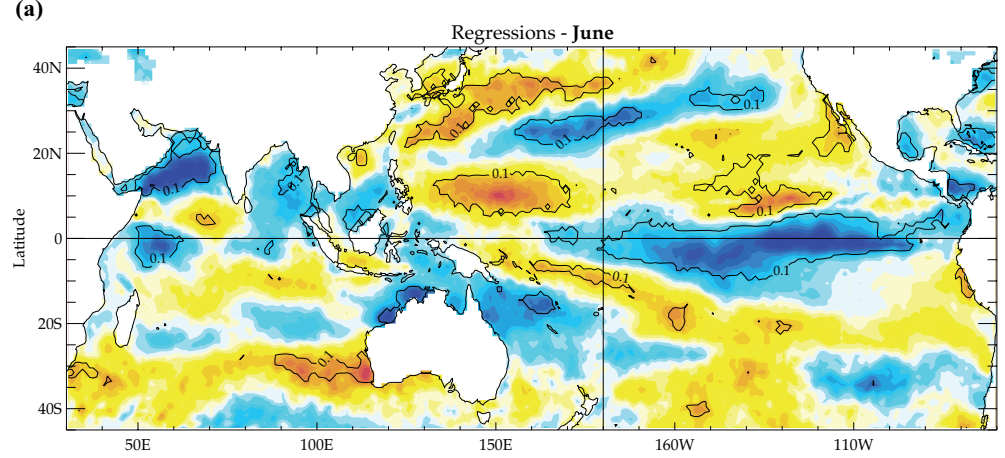

(b)

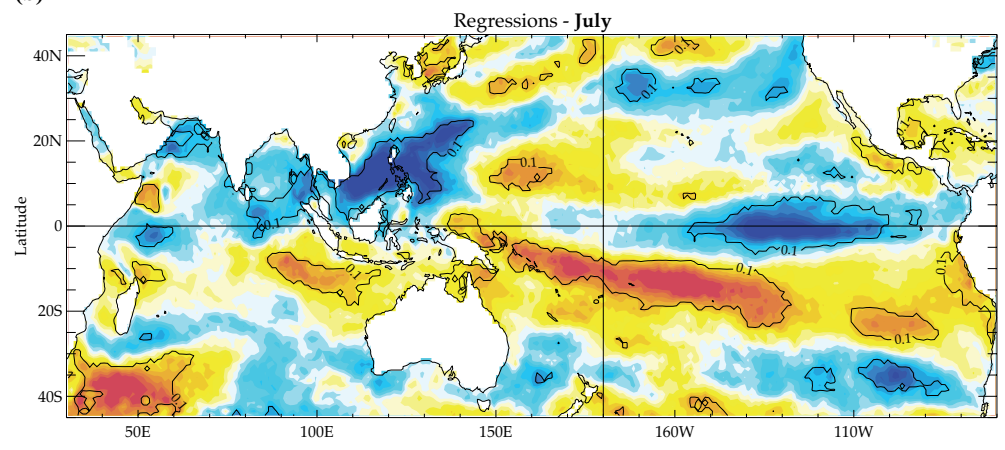

(c)
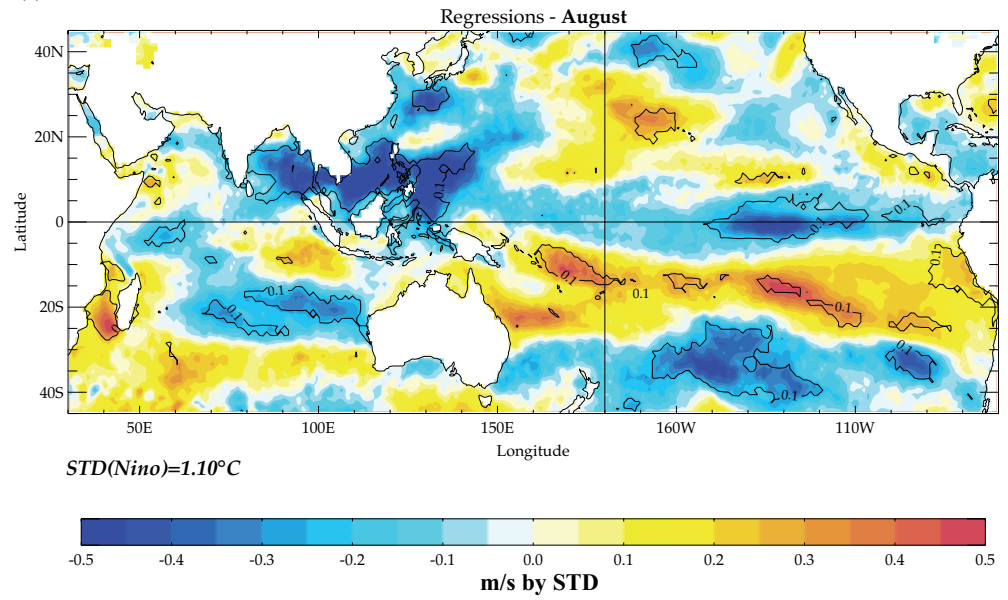

(d)

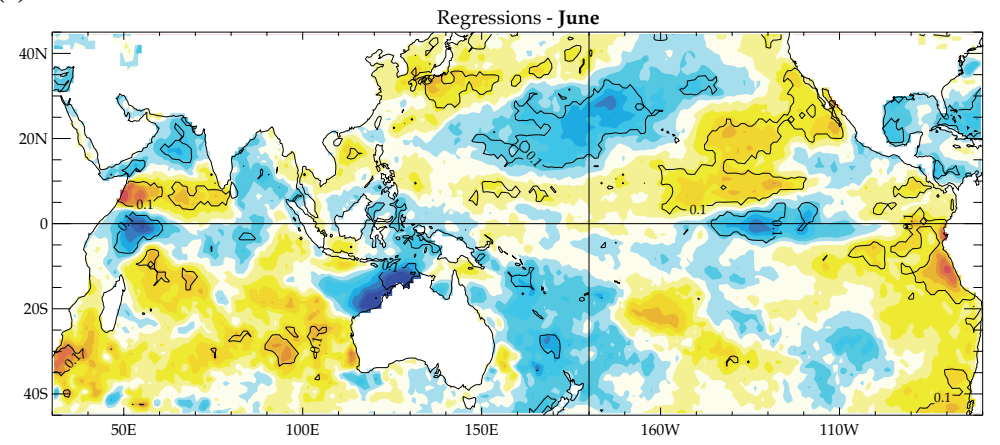

(e)

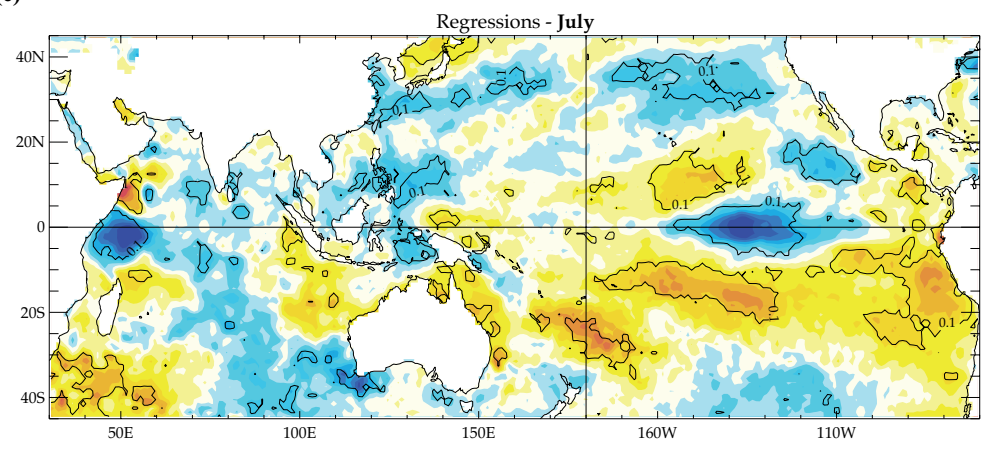

(f)

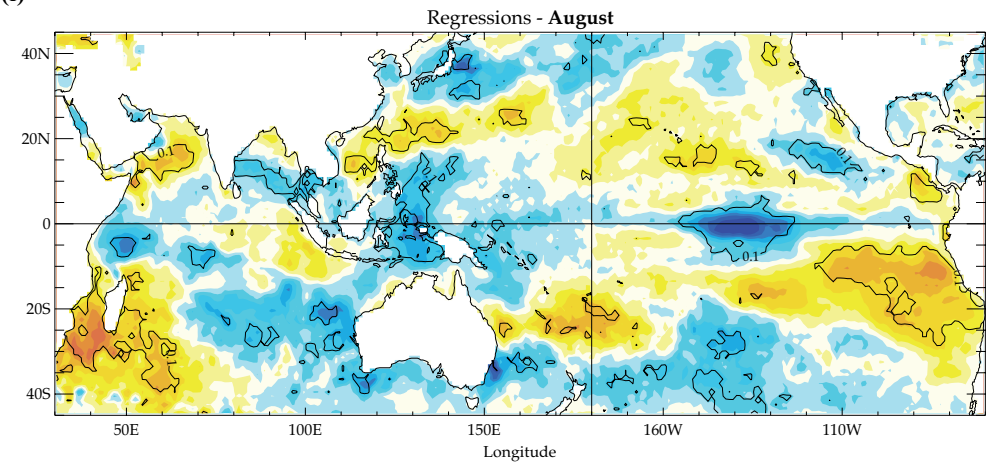

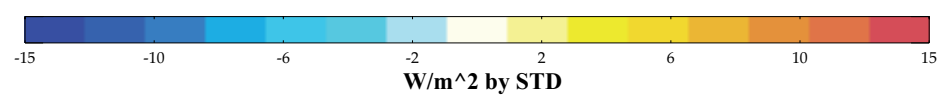


(a)

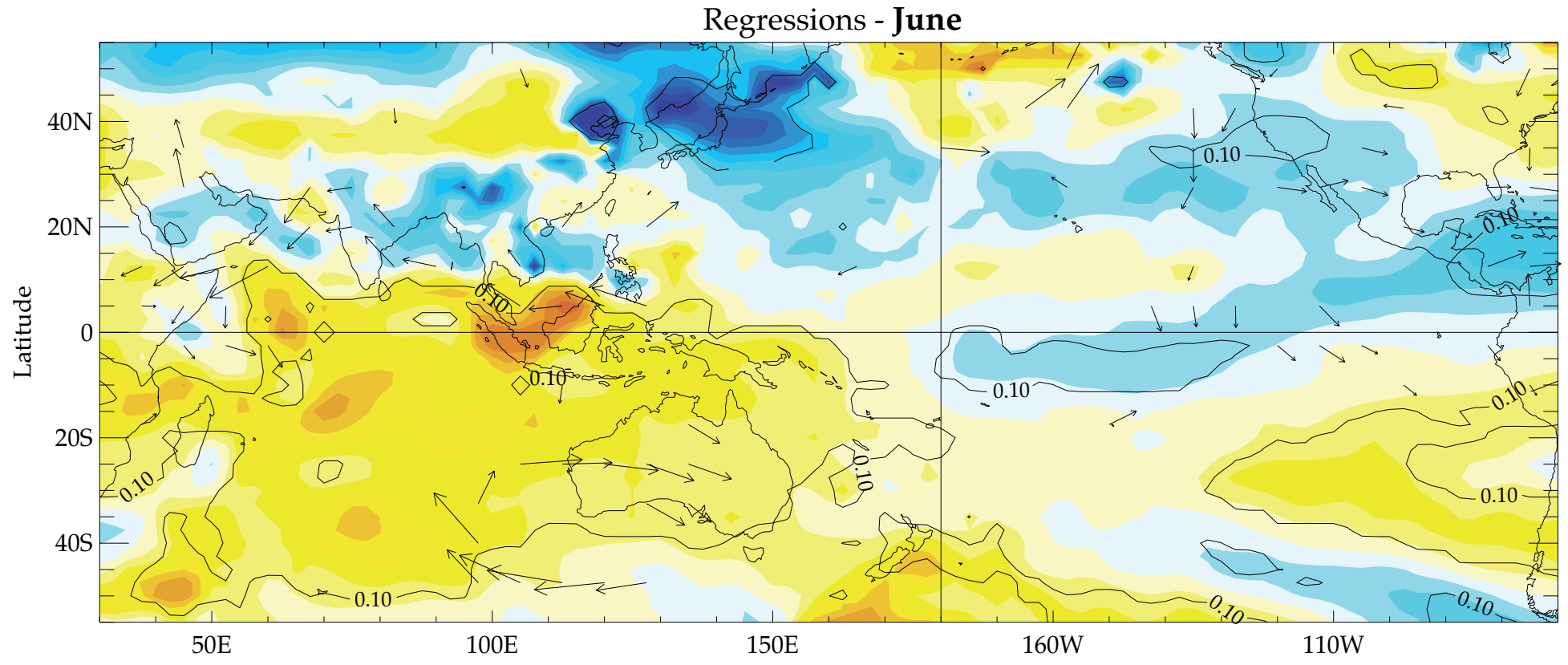

(b)

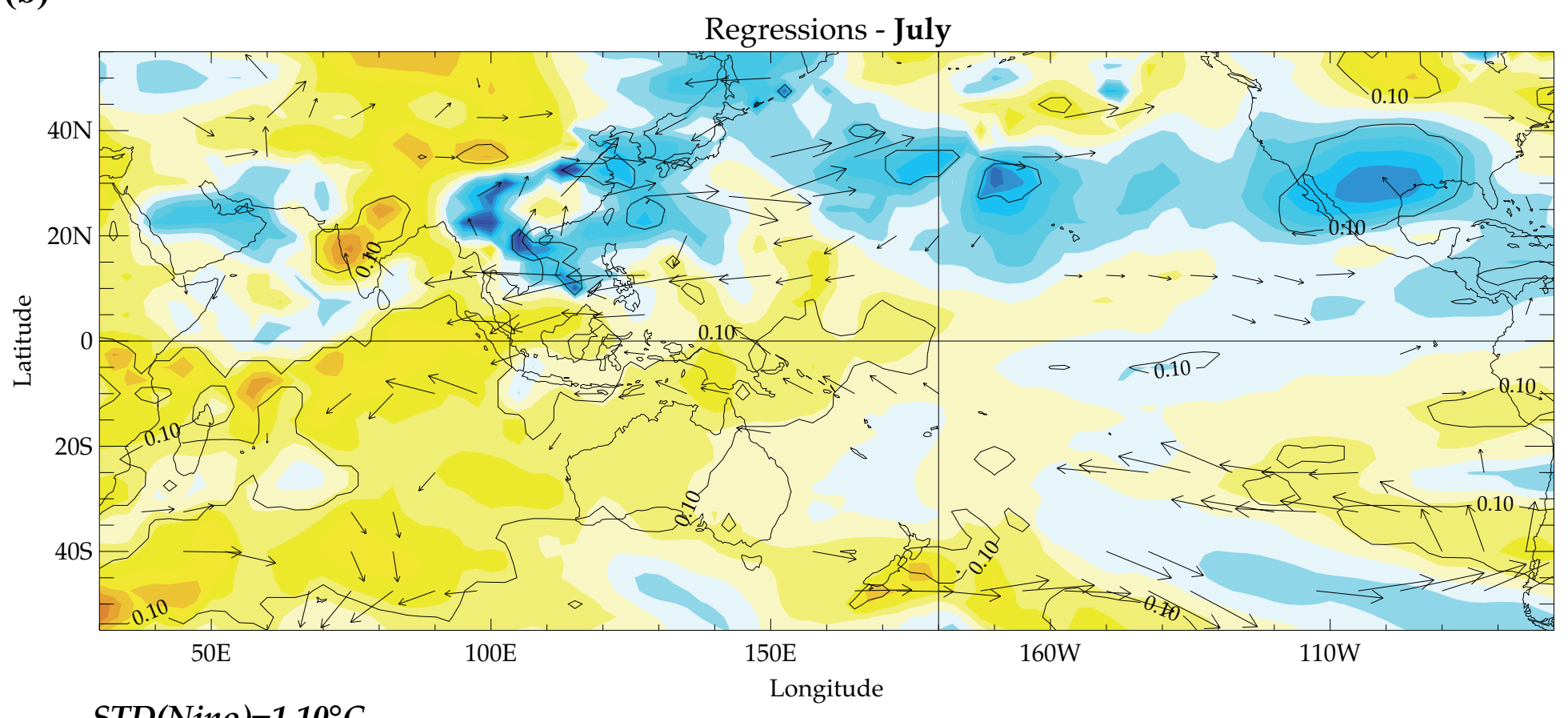

$S T D($ Nino $)=1.10^{\circ} \mathrm{C}$

$1 \mathrm{~m} / \mathrm{s}$ by STD 
(a)

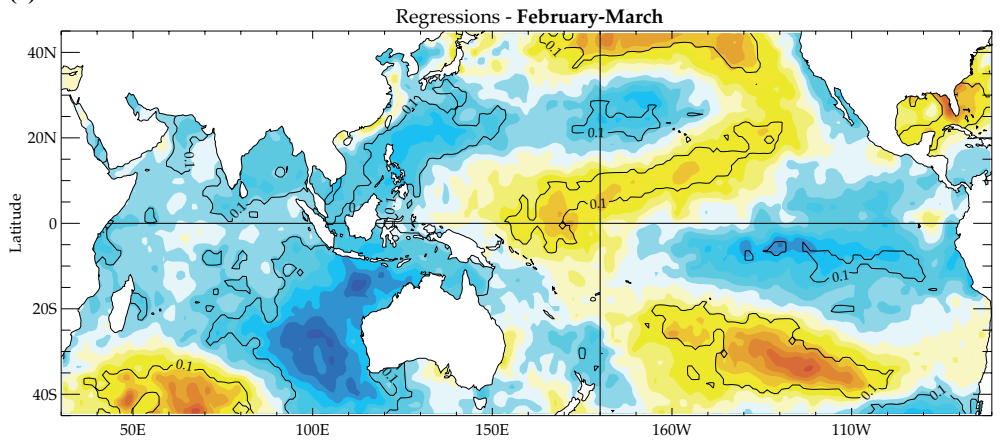

(b)

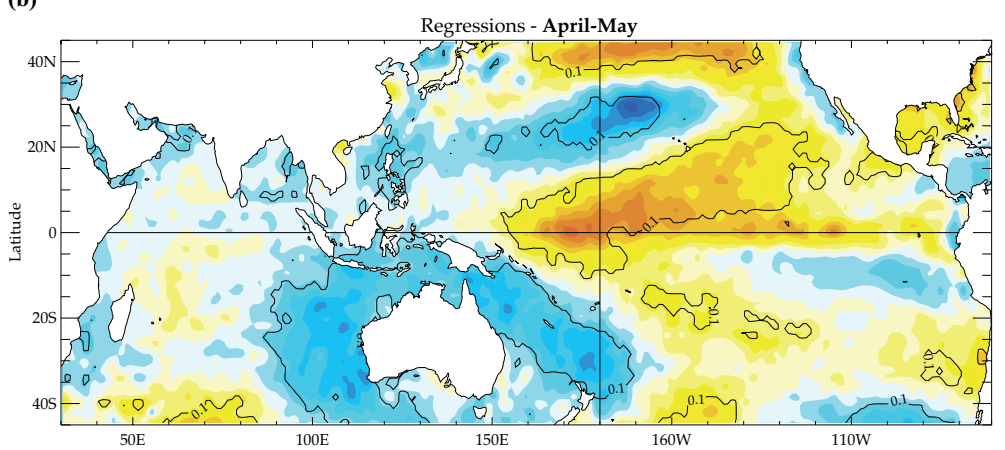

(c)

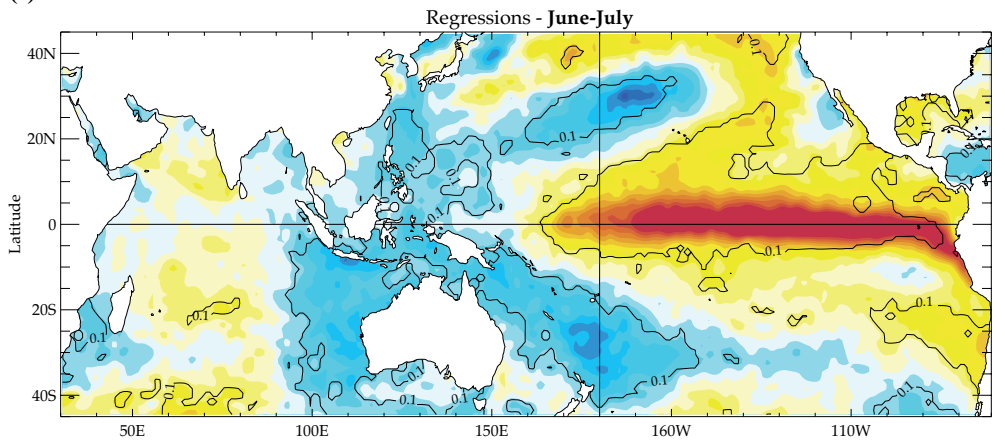

(d)

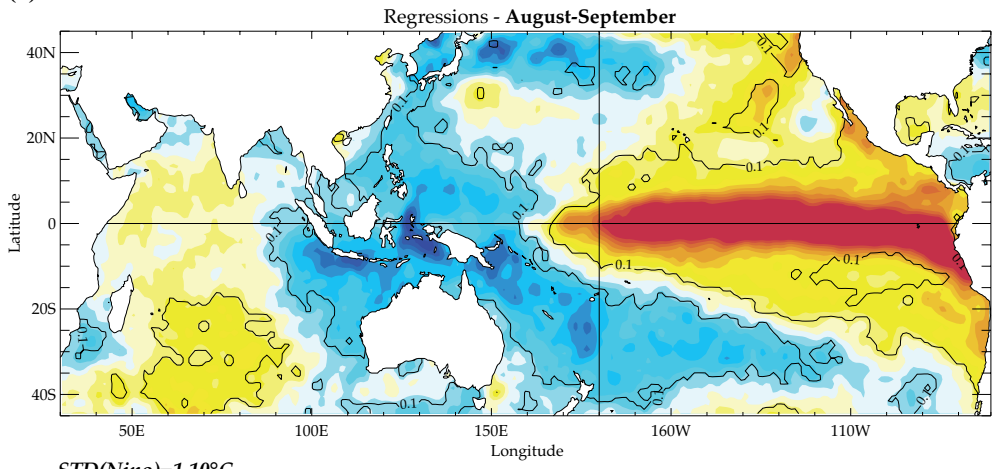

(e)

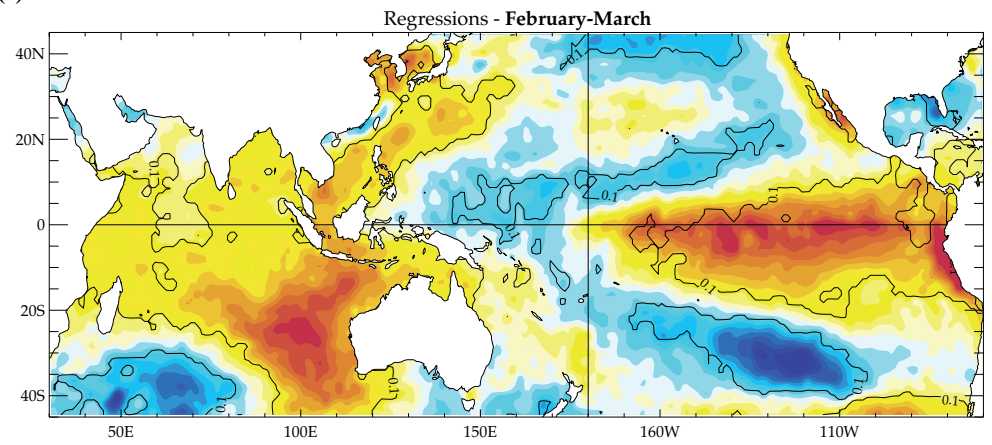

(f)

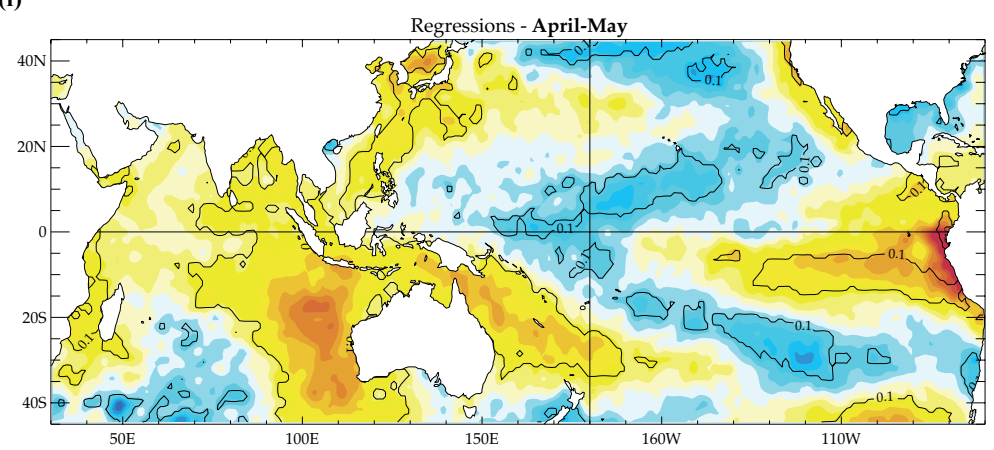

(g)

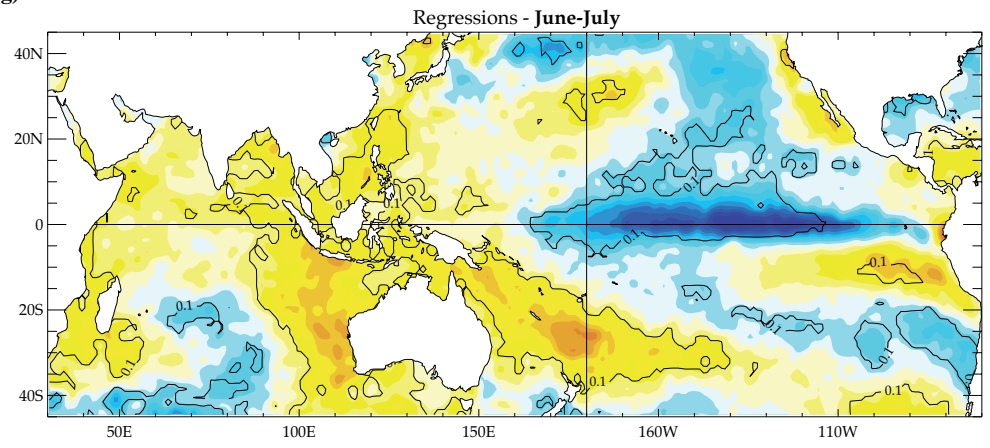

(h)

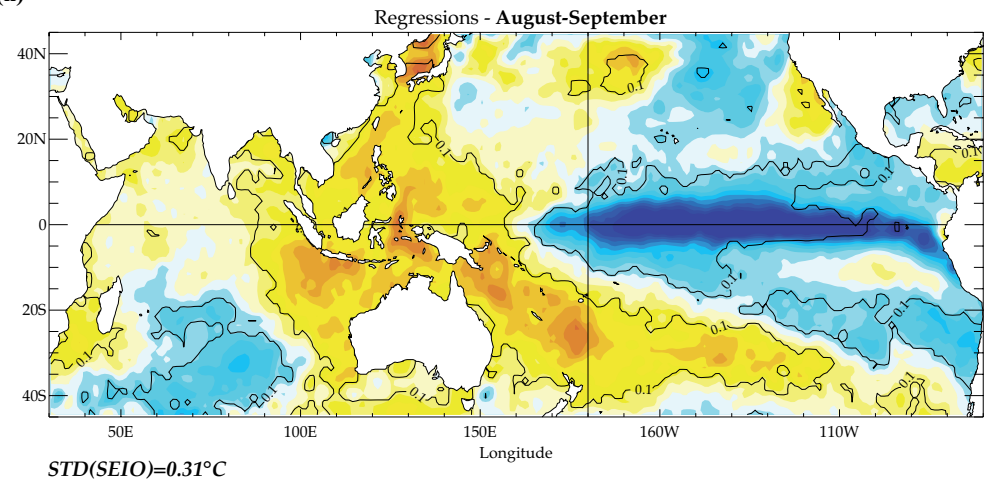


(a)
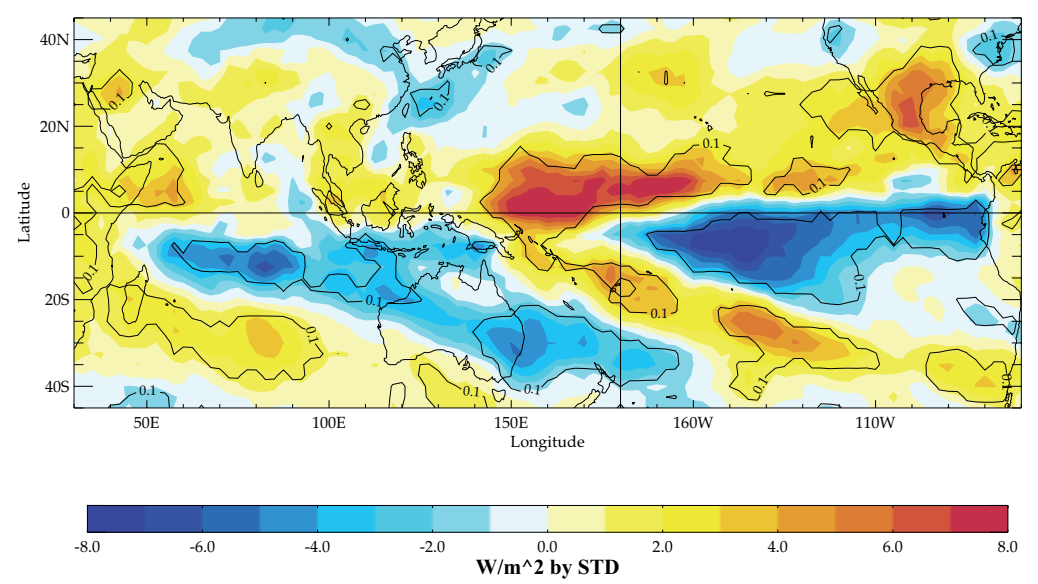

(b)

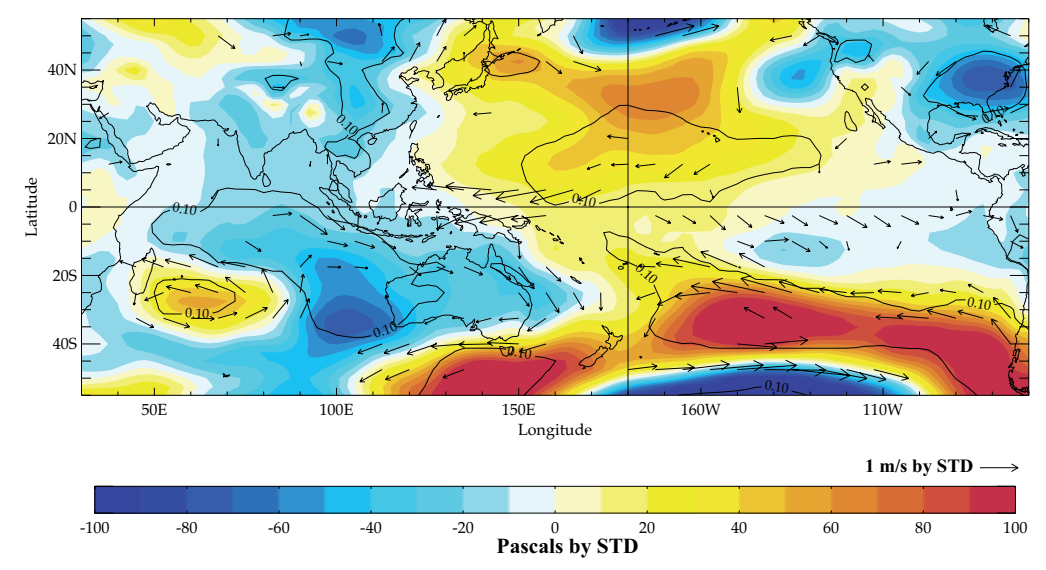

(c)
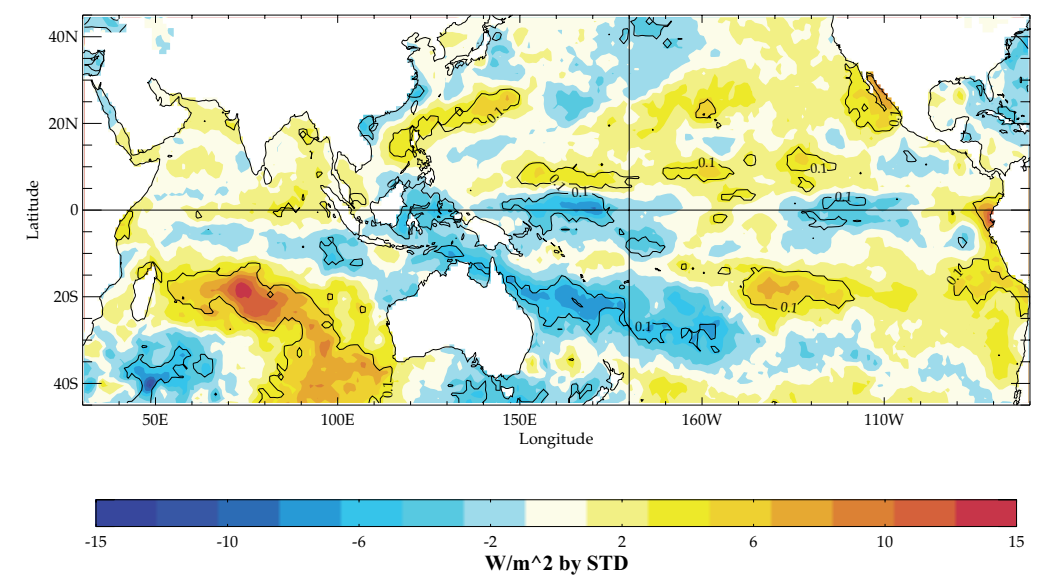

(d)

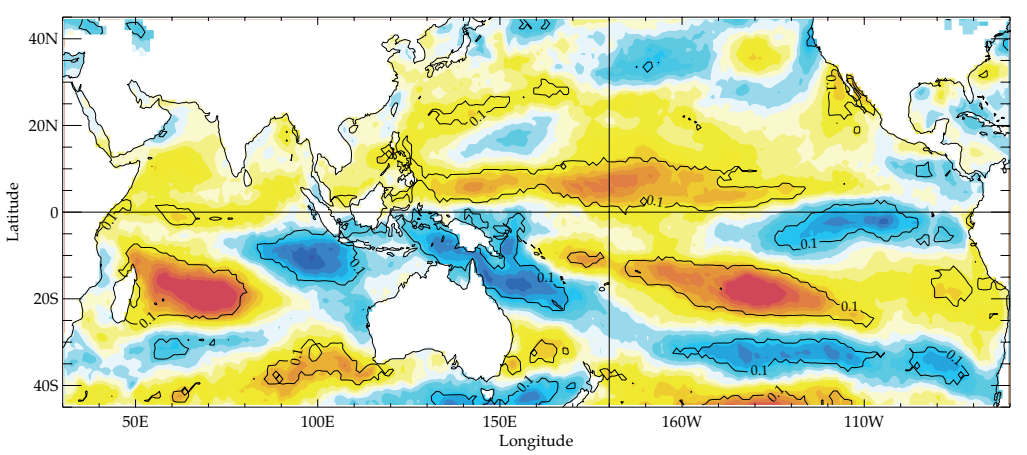

$S T D(S E I O)=0.31^{\circ} \mathrm{C}$

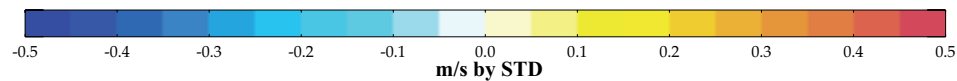


(a)

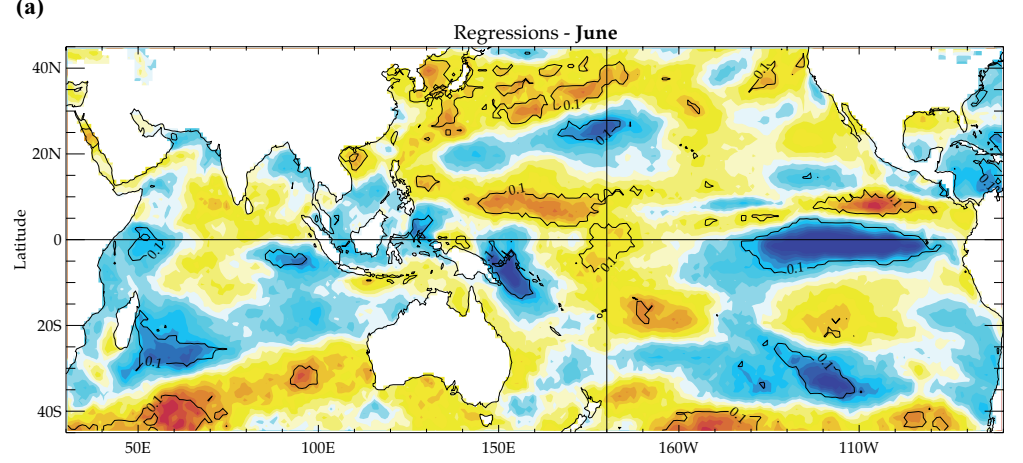

(b)

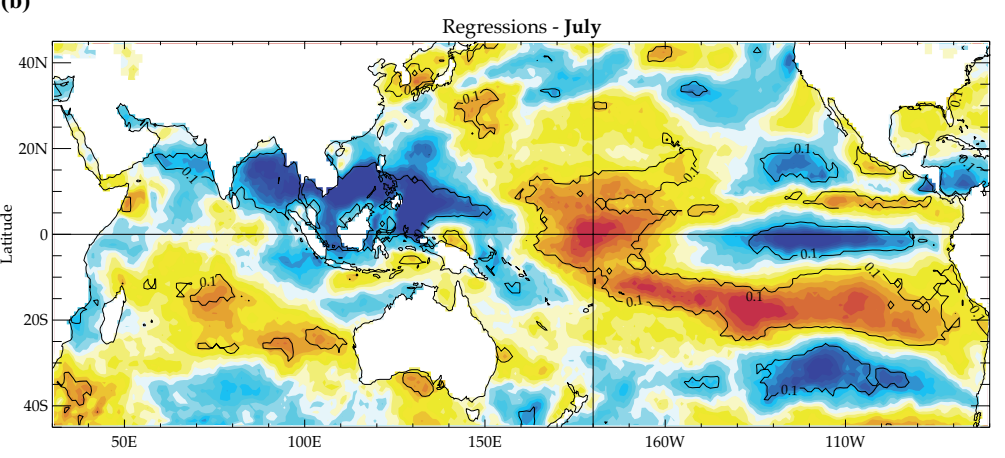

(c)

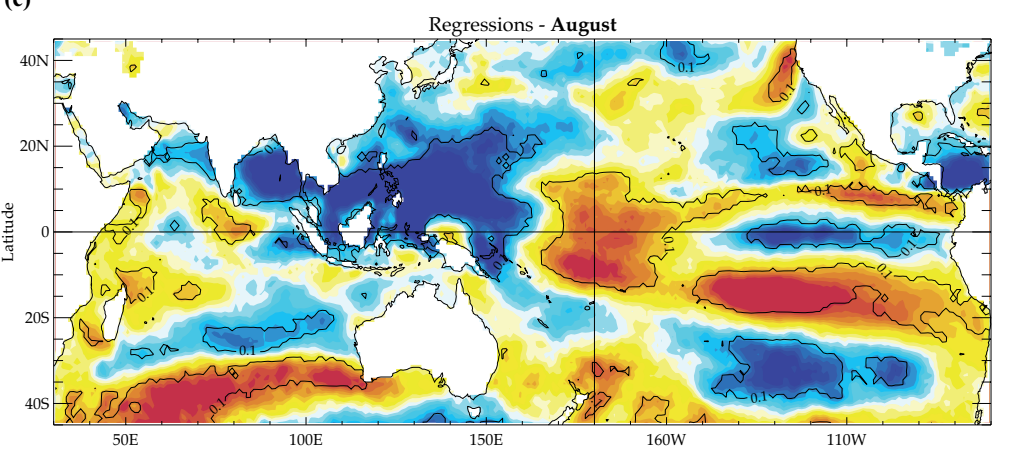

(d)

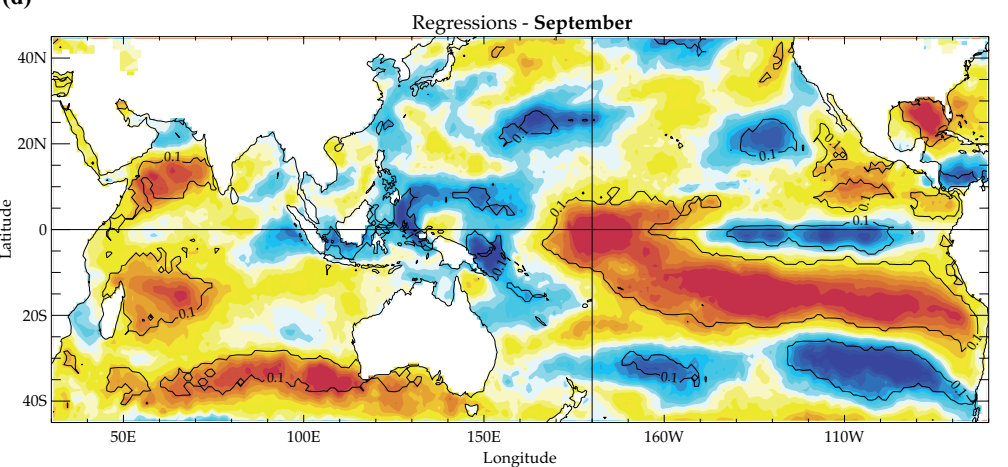

$S T D(S E I O)=0.31^{\circ} \mathrm{C}$ (e)

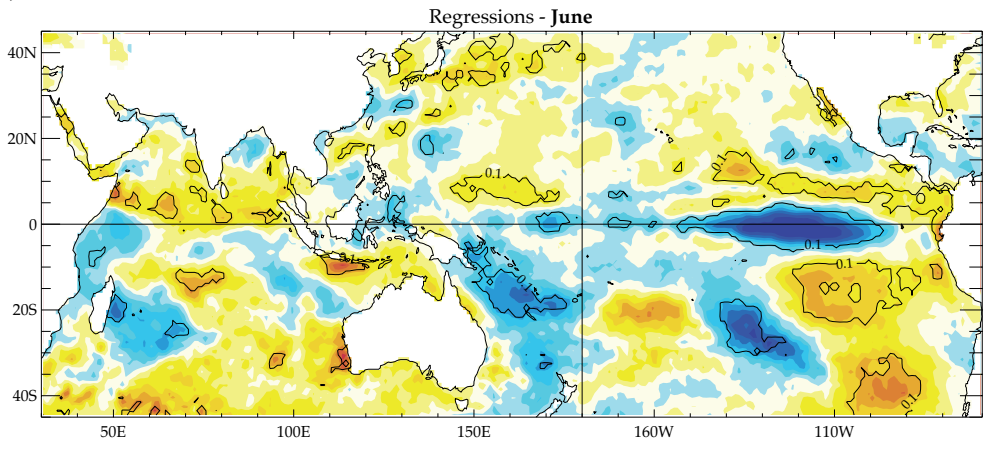

(f)

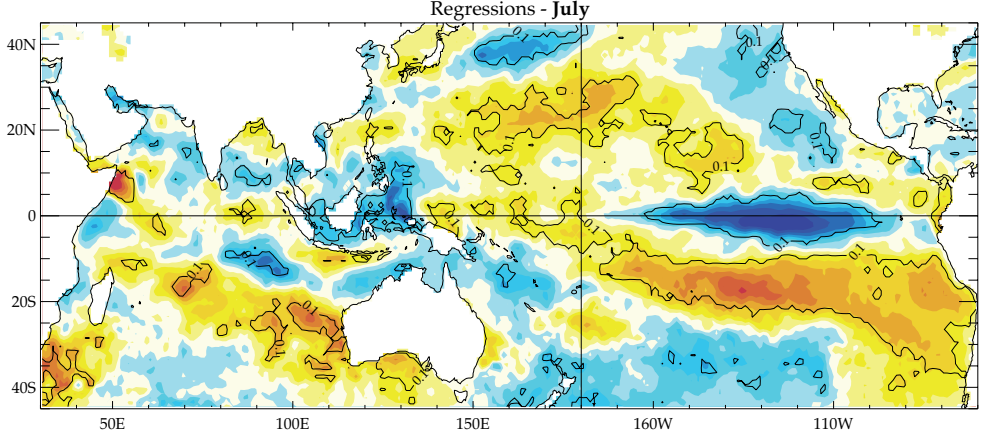

(g)

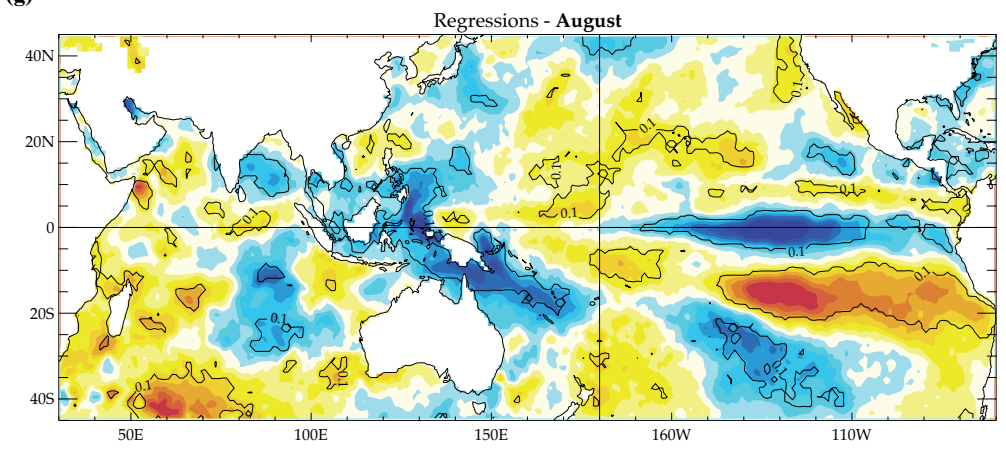

(h)

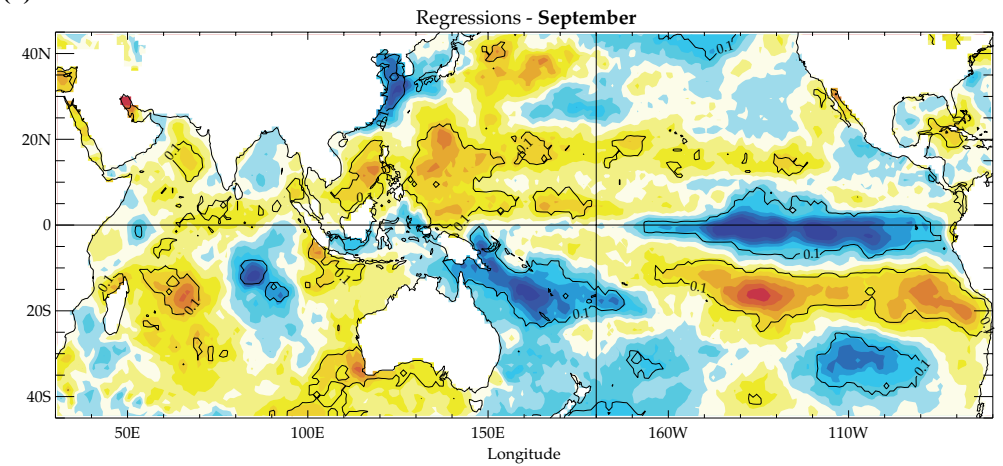

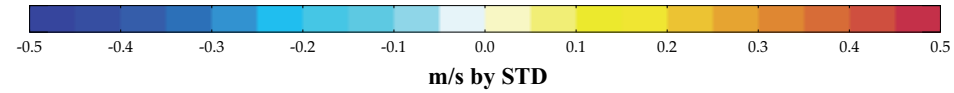

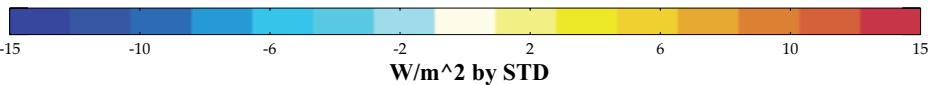


(a)

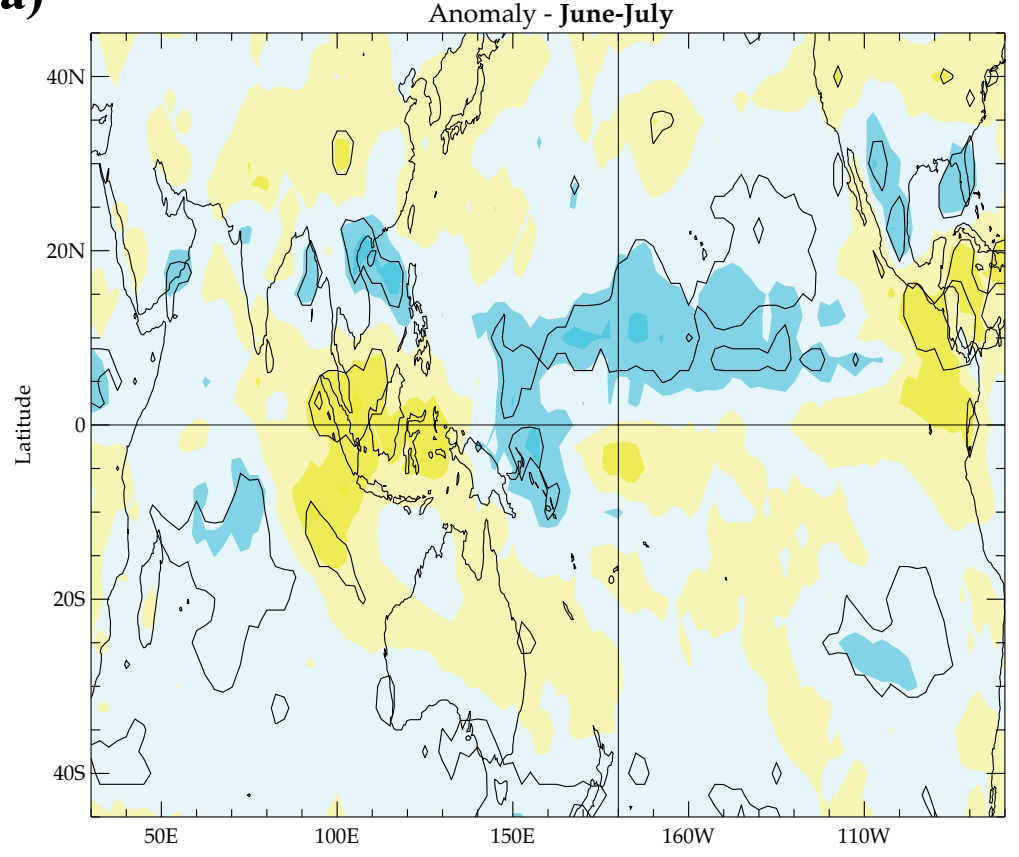

(b)

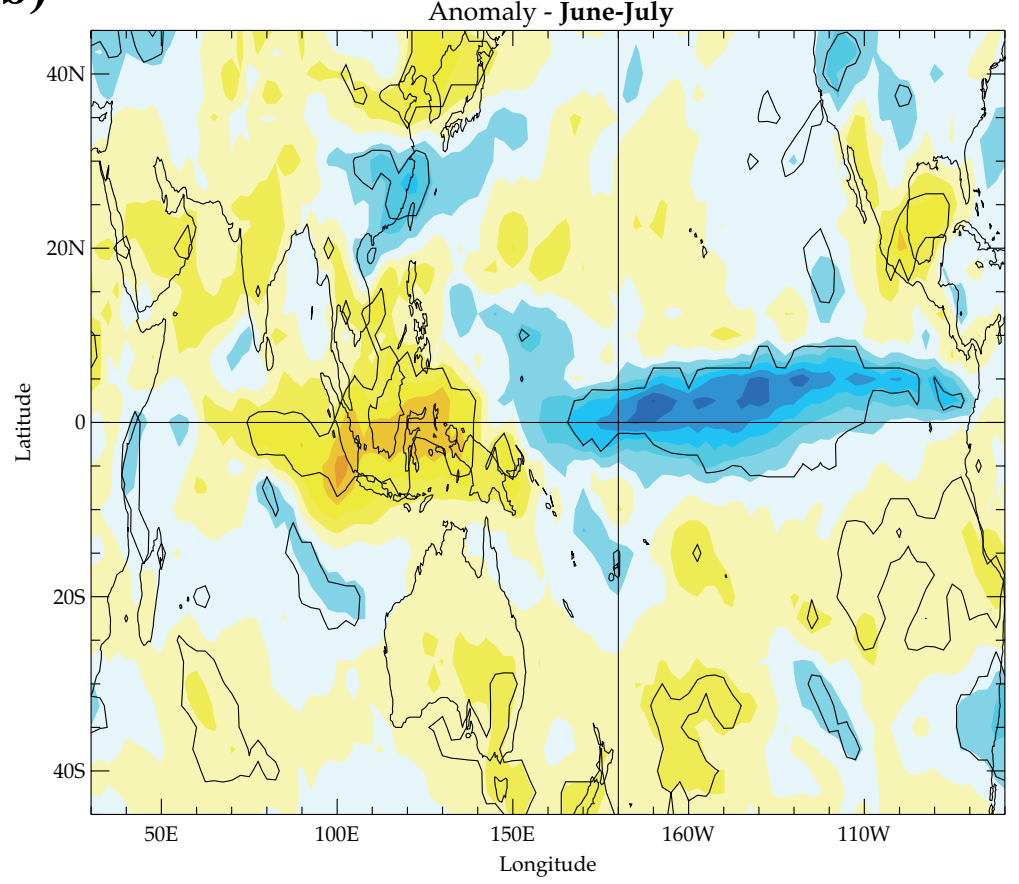

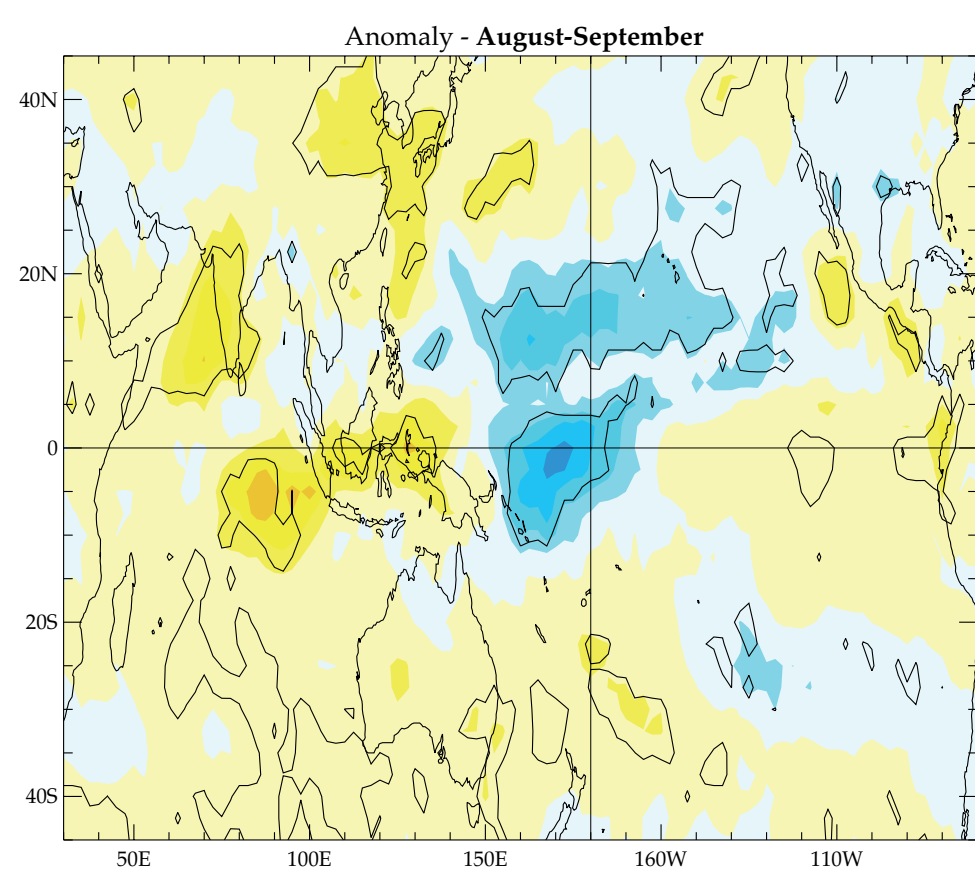

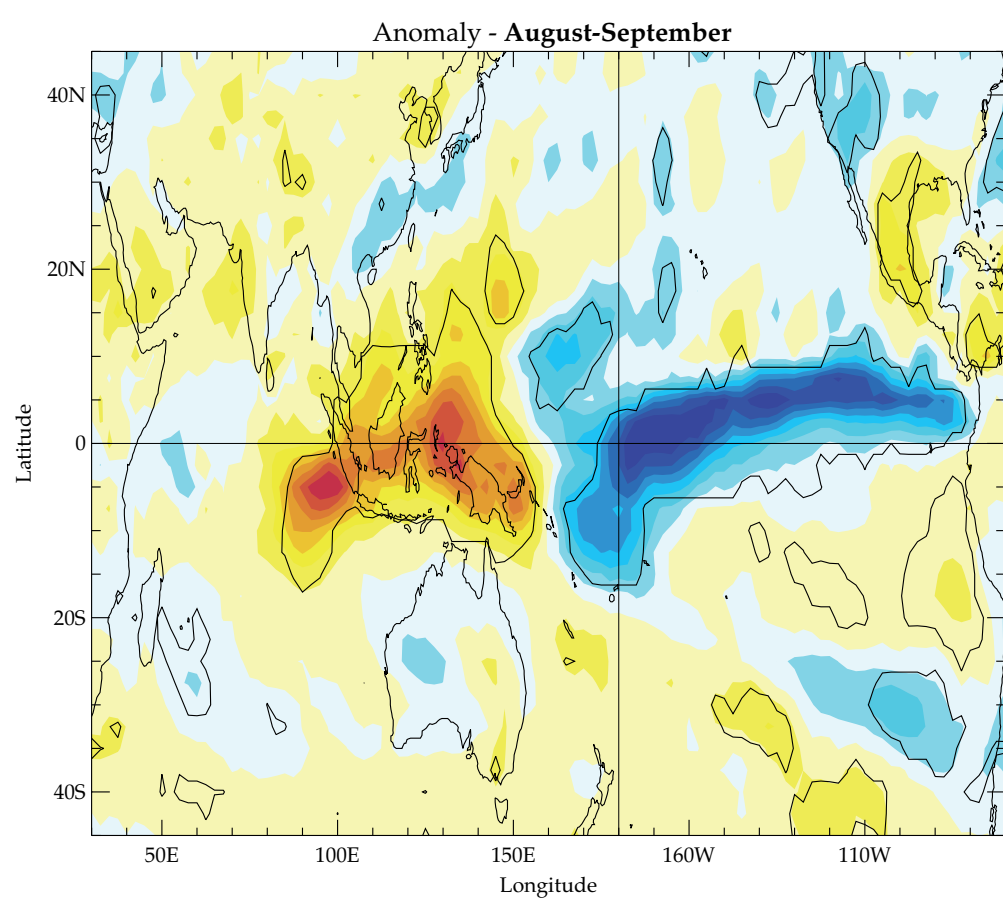


(a)

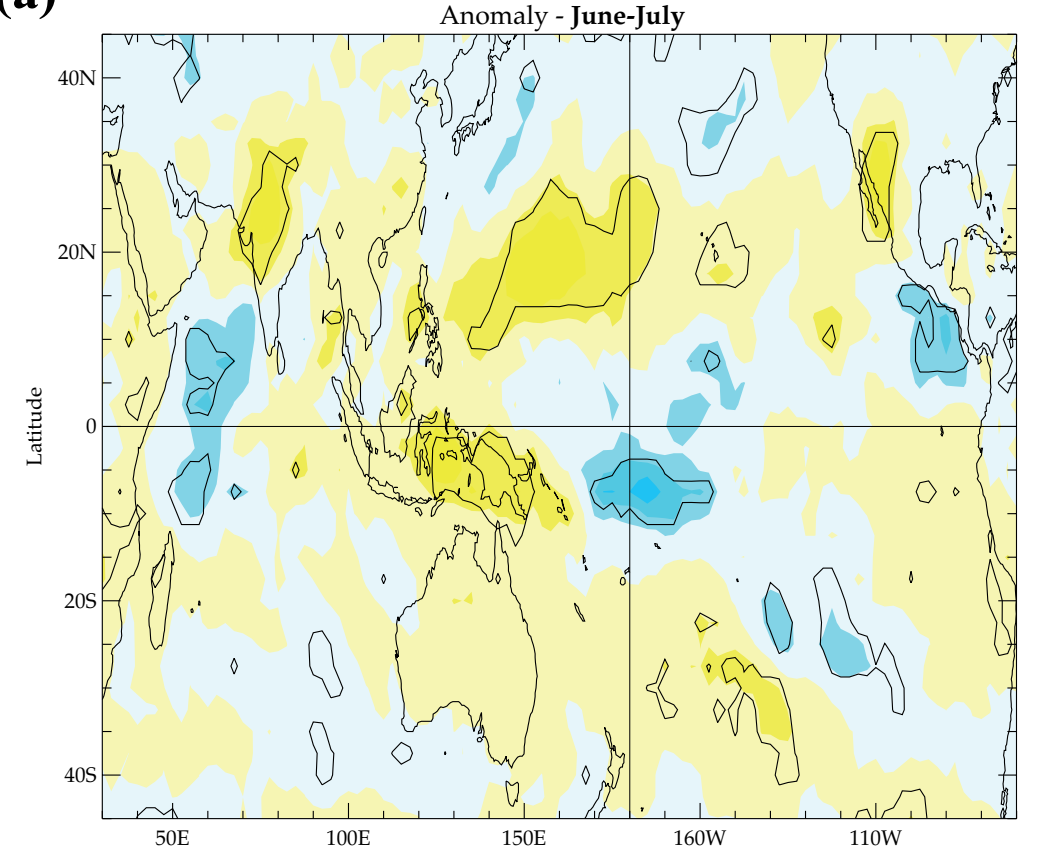

(b)

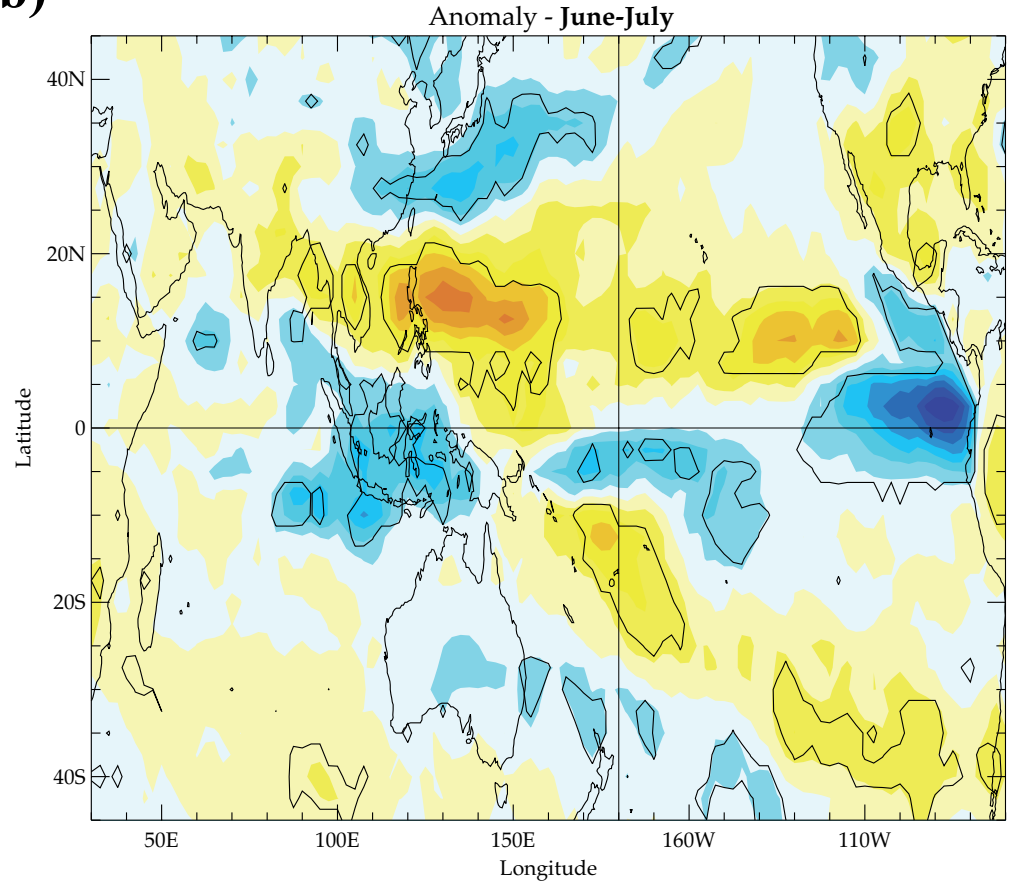

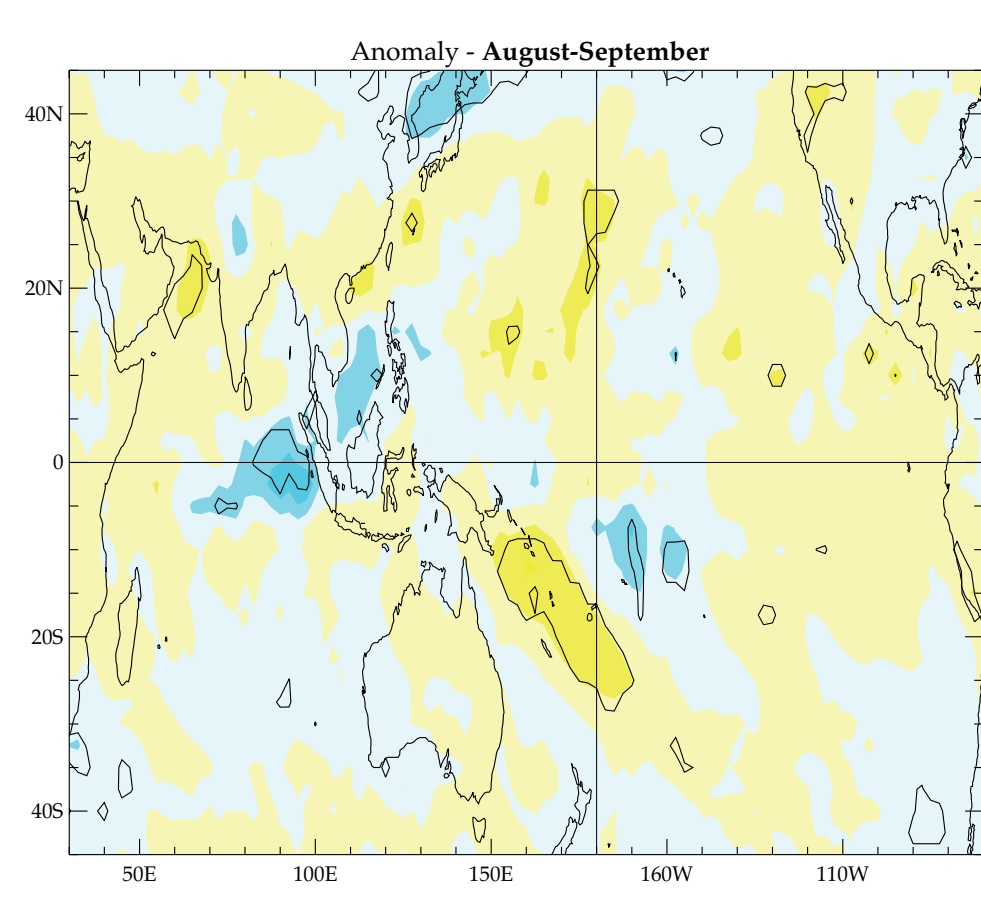

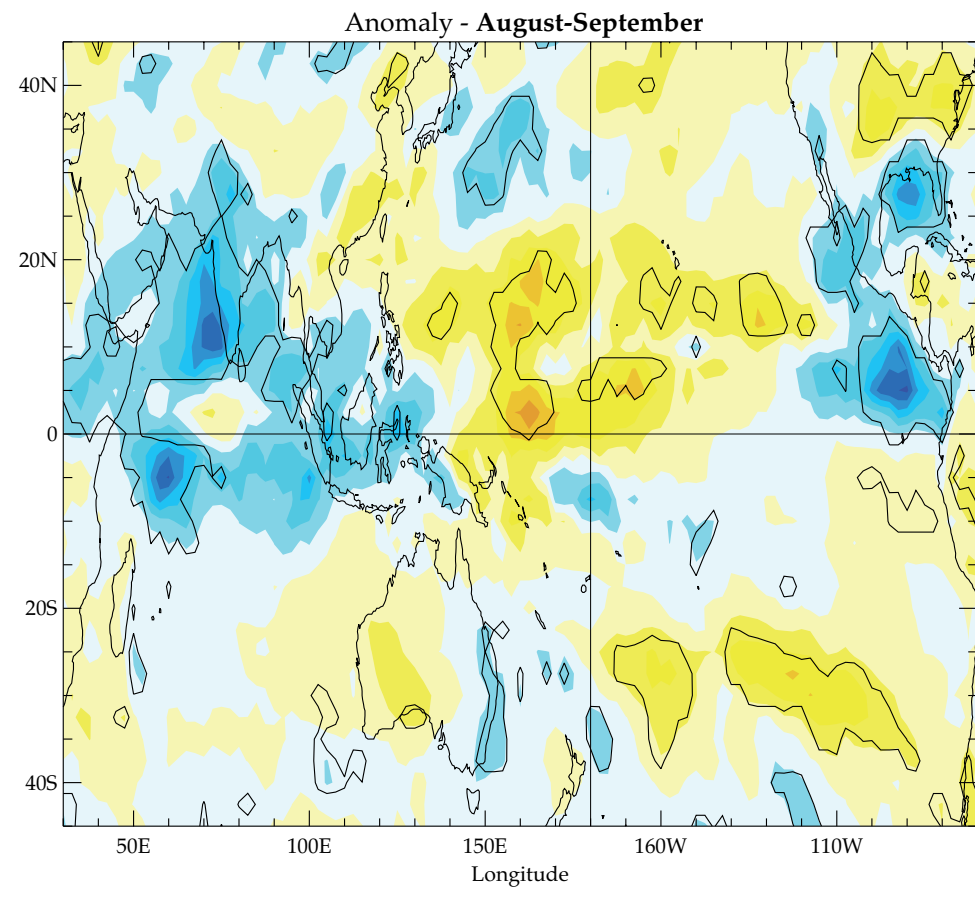

